\title{
¿UN SISTEMA DE CEQUES EN EL SHINCAL DE QUIMIVIL? ESPACIO SOCIAL Y ARQUEOASTRONOMÍA EN UNA CAPITAL INCAICA
}

\author{
A SYSTEM OF CEQUES IN EL SHINCAL DE QUIMIVIL? SOCIAL SPACE \\ AND ARCHAEOASTRONOMY IN AN INKA CAPITAL
}

Ricardo Moyanoa, Reinaldo A. Moralejob \& María Guillermina Cousoc

En este artículo se discute el concepto de ceque a partir de información etnohistórica para el área del Cusco y del estudio arqueoastronómico del sitio inca El Shincal de Quimivil, localizado en el Noroeste Argentino. Planteamos que las orientaciones analizadas estarían ligadas a la complementariedad y reciprocidad andina, donde la existencia de rumbos y huacas, se relacionarían con el simbolismo, la religión, el poder y la organización socio-política del Tawantinsuyu.

Palabras clave: Espacio social, Arqueoastronomía, Inca, Sistema de ceques, Noroeste Argentino.

In this paper we discuss the concept of ceque based on ethnohistorical information for the Cusco area and archaeoastronomy studies performed at El Shincal de Quimivil (Northwestern Argentina). We propose that this kind of spatial orientations would be linked to Andean complementarity and reciprocity, where rumbos (lines that are not necessarily straight) and potentially sacred places, or huacas, would be related to elements of Andean symbolism and religion, as part of domination strategies and socio-political organization in times of the Tawantinsuyu.

Keywords: social space, archaeoastronomy, Inca, system of ceques, Northwestern Argentina.

\section{INTRODUCCIÓN}

En este trabajo discutimos la existencia de posibles líneas ceques y orientaciones astronómicas en el sitio incaico El Shincal de Quimivil, así como las implicancias en las nociones de espacio social y las relaciones entre el sitio y su contexto geográfico, en el marco del estudio de la astronomía cultural y la arqueoastronomía. En este sentido, cabe destacar la ausencia de fuentes etnohistóricas para el área de estudio que hagan alusión a la existencia de ceques, razón por la cual será importante para nuestro análisis el uso de información proveniente del área central del Tawantinsuyu, el Cusco.

El Shincal de Quimivil se ubica en el centro-oeste de la provincia de Catamarca y constituye un centro político, administrativo y ceremonial; es decir, una capital provincial o huamani inca del Noroeste Argentino (Raffino 1983, 2004; Farrington 1999) (fig. 1).

El sitio se compone de diversas estructuras, sobre una superficie superior a las 30 ha, donde se destacan, como veremos más adelante, la plaza principal o haukaypata y una plataforma ushnu, cerros aterrazados,

A Ricardo F. Moyano Vasconcellos. Investigador Independiente, Buenos Aires, Argentina. Proyecto I+D UnLP (11/N806): "NOA. Historia, Arqueología y Paisaje". ORCID: 0000-0002-8153-0366. E-mail: astronomiaintercultural@gmail.com

B Reinaldo A. Moralejo. División Arqueología, Museo de La Plata. ConicET-Argentina. Facultad de Ciencias Naturales y Museo, Universidad Nacional de La Plata, Argentina. ORCID: 0000-0001-7305-6409. E-mail: reinaldomoralejo@yahoo.com.ar

c María Guillermina Couso. División Arqueología, Museo de La Plata. Facultad de Ciencias Naturales y Museo, Universidad Nacional de La Plata, Argentina. ORCID: 0000-0001-5679-9630. E-mail: mgcouso@hotmail.com 
diferentes tipos de kanchas y el Qhapaq Ñan, además de una posible intihuatana (roca vertical) y oquedades con fines astronómicos y rituales (Raffino 1983, 2004; Farrington 1999; Moralejo 2011; Giovannetti 2016). Existe consenso en pensar que El Shincal fue un "Nuevo Cusco", a partir no solo de la evidencia arqueológica y arquitectónica, que incluye elementos formales de lo que llamamos Inca, sino también de elementos vivos del paisaje presentes en los horizontes, a manera de huacas y marcadores calendáricos (fig. 2).

En términos teóricos, de un tiempo a la fecha, se han desarrollado nuevas perspectivas en torno a las relaciones (materiales, simbólicas e ideales) mantenidas entre los seres humanos y su entorno (Ingold 1993, Criado Boado 1991, Descola 2012). En ellas, el espacio es considerado, más allá de su dimensión física, como una elaboración social y resultado de la objetivación sobre el medio de las distintas acciones, experiencias y formas de pensar y subjetivizar el mundo. Desde esta visión, las sociedades humanas construyen su espacio y lo organizan en función de las distintas lógicas que estructuran sus relaciones con el entorno, asumiendo siempre un sentido relacional y ligado tanto con las prácticas sociales como a los sistemas ontológicos presentes en cada cultura (Iwaniszewski 2007, Descola 2012). En esta línea de trabajo, la Arqueología del Paisaje y la Arqueoastronomía se incluyen en los estudios del espacio y surgen como propuestas disciplinares que permiten superar enfoques ecologistas y funcionalistas acerca de la ocupación del entorno y el modo de establecimiento, como aquellos modelos ecológico-adaptativos y de optimización de los recursos de la Arqueología histórico-cultural y procesual (Criado Boado 1991, Iwaniszewski 1995). Al respecto, numerosos estudios etnográficos y etnohistóricos trataron sobre las nociones y categorizaciones del espacio y del tiempo en diferentes sociedades andinas, y sus relaciones con la observación del cielo y la conformación de espacialidades cargadas de significación. En ellos sobresale la concepción cíclica del tiempo, las dinámicas de sacralización del espacio, en las que gravitan los cultos a las montañas, huacas y ancestros, las lógicas locales que intervienen en la percepción y categorización del cielo y fenómenos astronómicos, la relevancia de las relaciones de reciprocidad en las interacciones entre los humanos, y entre estos y los no-humanos y las divinidades, así como también la complementariedad de espacios y ambientes ecológicos (Murra 1972; Hyslop 1990; Zuidema 1995, 2011; D’Altroy 2003; Ziólkowski 2015).

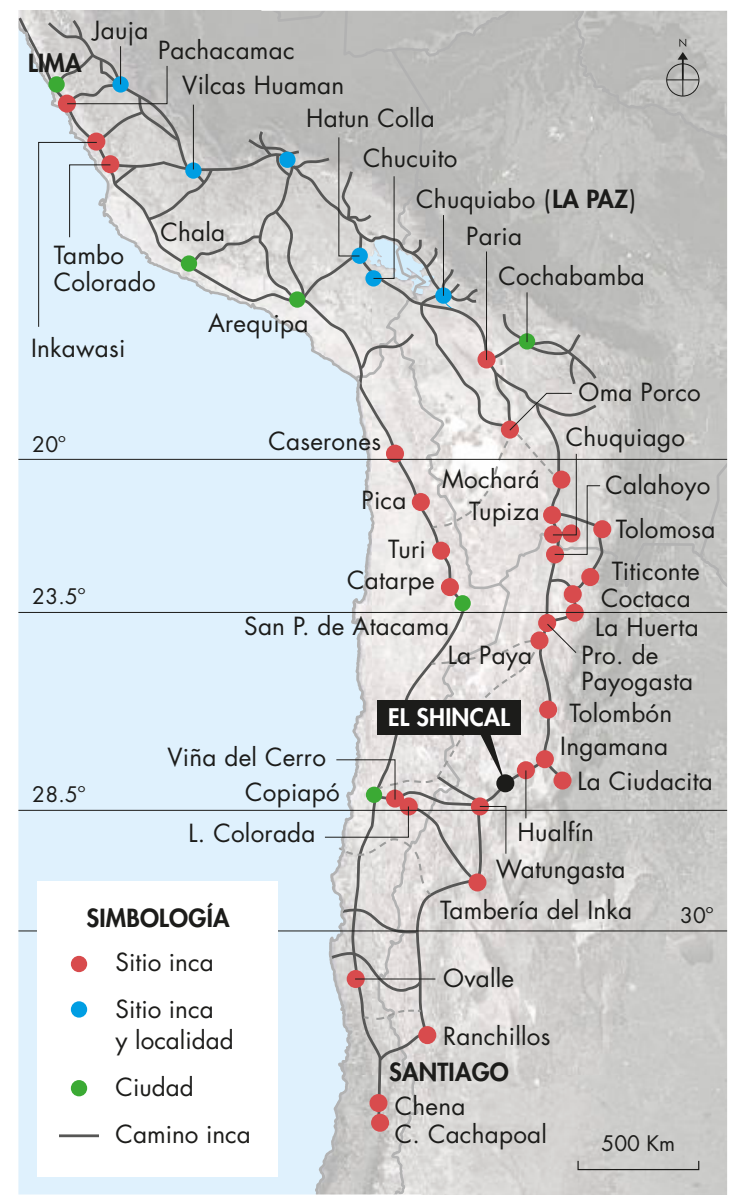

Figura 1. Mapa de ubicación general (tomado y modificado de Moralejo \& Gobbo 2017: 327, figura 1). Figure 1. General location map (taken and modified from Moralejo \& Gobbo 2017: 327, figure 1).

Sostenemos como hipótesis que la organización del espacio y el modo de vida en el sitio El Shincal de Quimivil respondió a lógicas funcionales, económicas y políticas, a la vez que simbólicas y de orden astronómico. Aquí, el espacio es considerado como un producto sociocultural formado por la objetivación de la acción humana y sus prácticas sociales recurrentes sobre el medio material circundante (Soja 1971, Lefebvre 1976, Criado Boado 1991, Acuto 2012). En este sentido, el cielo se entiende como parte del paisaje, y no solo un fenómeno físico y abstracto, sino más bien el resultado de la proyección y configuración de valores, normas y categorías humanas en el entorno, así como el reflejo de las relaciones y categorías sociales mantenidas entre los humanos, los no-humanos y el medio físico (Iwaniszewski 2007; Ruggles 2015; Leibowicz et al. 2016, 2018). 


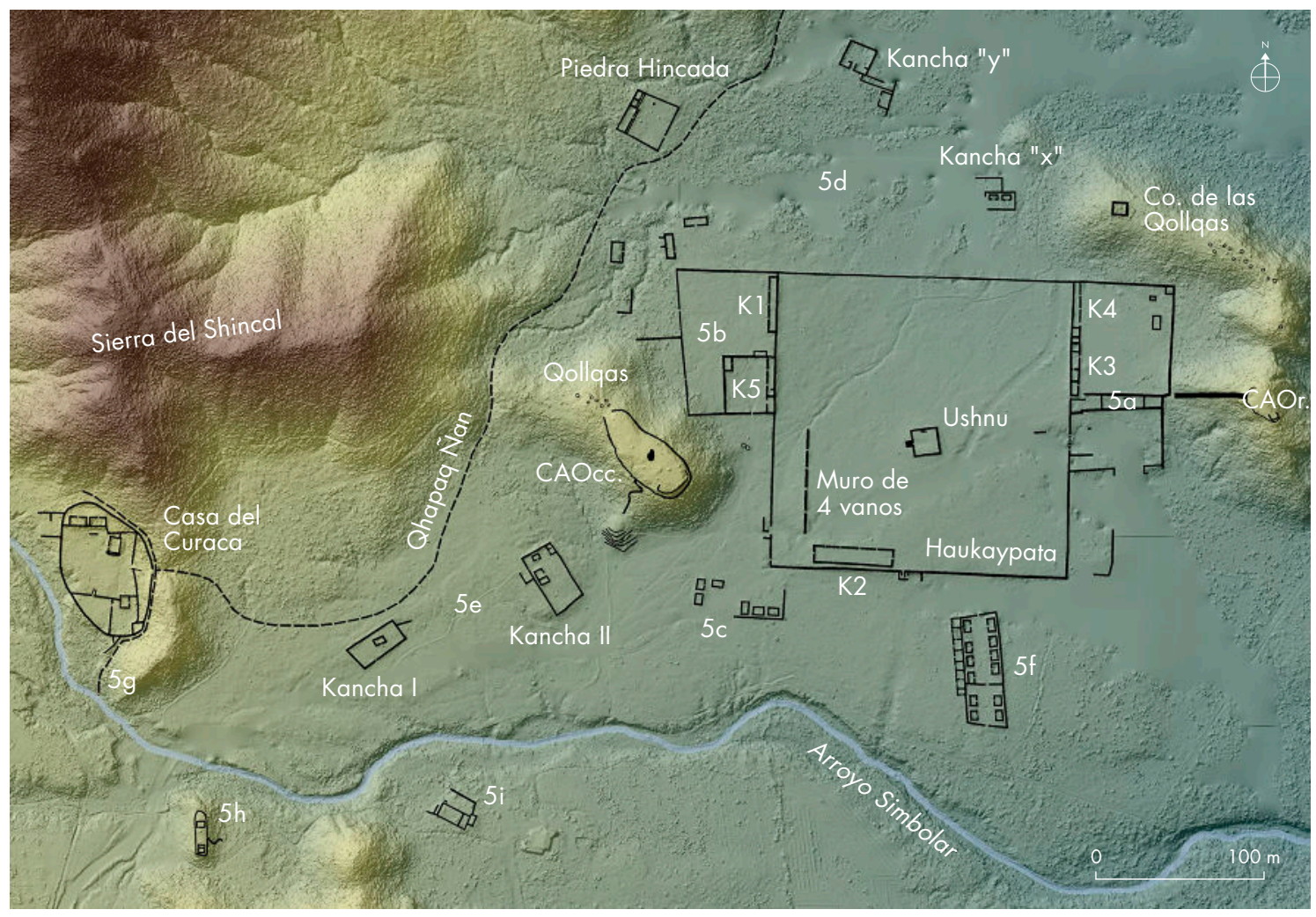

Figura 2. Plano del sitio El Shincal de Quimivil actualizado con tecnología LIDAR (Light Detection and Ranging). Figure 2. Plan of El Shincal de Quimivil site updated through LIDAR (Light Detection and Ranging) technology.

\section{¿QUÉ ES UN SISTEMA DE CEQUES?}

La observación del cielo en los Andes, al igual que en otras partes del mundo, fue referente para el origen de leyendas, cosmogonías y estructuras sociales. En particular se sabe de la relación sagrada que tenía la elite inca con el Sol, la Luna, algunas estrellas, planetas y zonas de la Vía Láctea a través de ceremonias que tenían lugar en momentos de solsticios y equinoccios, plenilunios, salidas y puestas de estrellas, además de eventos irregulares como eclipses, cometas y fenómenos atmosféricos. Todo ello estaba articulado dentro del sistema de ceques (Zuidema 1989, 2011; Bauer \& Dearborn 1998; Ziólkowski 2015). Esta relación claramente volvía difusa la diferencia entre naturaleza y cultura, debido a que incluía entidades humanas, no-humanas y sobrenaturales que también estaban presentes en la organización del propio Cusco: hanan o arriba (Chinchaysuyu y Antisuyu) y hurin o abajo (Collasuyu y Cuntisuyu) (Bauer 2016).
Un sistema de ceques, según las descripciones de los cronistas españoles, se define como un conjunto de 41/42 líneas o direcciones proyectadas desde el templo del Sol o Coricancha en la ciudad del Cusco. González Holguín (1952 [1608]: 79) se refiere a "ceqque" como raya, línea o término. Bertonio (1612: 293) habla de "seke" como una línea. Por su parte, Rowe (1981: 211) hace referencia a "zeq' e" como cualquier tipo de línea en lengua quechua. Este sistema tenía por función organizar al menos 328 huacas (wak'as) o adoratorios, tales como rocas, manantiales, cerros o construcciones durante el desarrollo y apogeo del Tawantinsuyu (mundo de los cuatro suyus) (Rowe 1981; Zuidema 1995, 2011; Bauer 1998, 2016; Bauer \& Dearborn 1998).

Si bien no todas las huacas descritas por Cobo (1892 [1653]) tenían una finalidad astronómica, se asume que de un total de 350 solo 328 estarían destinadas a fines calendáricos precisos (Zuidema 2011). Este número equivaldría a 12 meses lunares siderales de 27,3 días -más 37 días restantes para completar la 
cuenta solar de 365- obtenidos ritualmente, a través del seguimiento del periodo de invisibilidad de Las Pléyades, entre los días 3 de mayo y 9 junio, que coincidían también con el inicio del calendario ritual en la ciudad del Cusco (Zuidema 2011). Estas direcciones regulaban las relaciones de parentesco, las jerarquías políticas, el tributo y las principales fiestas, dentro de un esquema calendárico que tomaba en cuenta los movimientos del Sol, los ciclos de la Luna y la observación conjunta de estrellas y zonas oscuras de la Vía Láctea (Zuidema 1995, 2011). Hoy existen al menos dos posiciones con relación a la forma y naturaleza de los ceques. Zuidema (1995), basándose en diversa información procedente de las crónicas, los interpretó como trazos rectos que conformaban líneas de mira desde el Coricancha hacia el horizonte en la ciudad del Cusco. Mientras que Bauer (1998), a partir del uso de la arqueología de campo y documentación virreinal, proyectó los ceques como líneas no siempre rectas, en zigzag y en algunos casos con direcciones diferentes. Bauer (2016), mediante el análisis del Exsul immeritus Blas Valera populo suo y la crónica del padre Bernabé Cobo, disiente de los trabajos de Zuidema (2007), y concluye que habría discrepancias entre las dos fuentes y la organización del número de huacas en el Cuntisuyu y los otros suyus. Según Bauer (2016), Zuidema se equivocaría en la suma de las huacas en las líneas collana, payan y cayao. Asimismo, sostiene que el dibujo sería exacto a partir de una cuenta decimal que daría una lectura de los ceques y huacas -en sentido de las manecillas del reloj para Chinchaysuyu y Antisuyu, y contrario a las manecillas del reloj para Cuntisuyu y Collasuyu-igual a 328 huacas (Bauer 2016). En principio, esto no debería afectar, en estricto rigor, las funciones astronómicas y calendáricas de los ceques, en la medida en que atienden a prácticas rituales en momentos específicos del año (Zuidema 2011). Según la Relación de los Ceques, de la crónica del padre Cobo (1892 [1653]), basado en documentos y manuscritos anteriores (Rowe 1981), el mantenimiento y culto de estos lugares sagrados o huacas estaban asignados a ciertos grupos sociales (panacas y ayllus), mientras que su división espacio-territorial estaba organizaba en cuatro barrios: con 9 ceques y 85 huacas en Chinchaysuyu, 9 ceques y 78 huacas en Antisuyu, 9 ceques y 85 huacas en Collasuyu, y 14 ceques (con un ceque doble) y 80 huacas en Cuntisuyu. Esto hacía un total de 328 huacas. A esta lista y sin un aparente sentido calendárico, se sumaría el Coricancha, cuatro huacas extras en los cerros de la región y los restantes (quizás 17) pilares que marcarían los meses del año, dando un número total de 350 huacas (Cobo 1892 [1653]). Cada suyu dividía sus ceques en tres grupos de tres líneas, recibiendo los nombres genéricos de Collana (a), Payan (b) y Cayao (c). Los mismos referían a las jerarquías de cada grupo social en hanan Cusco (arriba) y hurin Cusco (abajo), y a los principios andinos de reciprocidad y redistribución en términos sociales, políticos, económicos y religiosos (Rowe 1981, Zuidema 1995).

Estas 41/42 líneas o ceques, según el padre Cobo, tenían la siguiente secuencia dentro de cada suyu (Zuidema 1995): Chinchaysuyu: cba, cba, cba; Antisuyu: abc, abc, abc; Collasuyu: cba, cba, cba; y Cuntisuyu: b, cba, cba, (ca), cba, cba. La secuencia de los ceques en Chinchaysuyu y Antisuyu estaba ordenada en el sentido de las manecillas del reloj (a, b, c). Por su parte, en Cuntisuyu y Collasuyu se respeta la secuencia $(a, b, c)$, pero en sentido contrario a las manecillas del reloj. De acuerdo con lo dicho, si se parte con los ceques de Chinchaysuyu desde el oeste, se inicia con un ceque Collana, es decir, "el primero, el más prominente", donde cada grupo de tres ceques se señala con números arábigos $(1,2,3)$ en orden de importancia (Zuidema 1995: 70, 2011:25). El mismo Zuidema (2011) complementa esta información con los datos de Cristóbal de Molina "el Cuzqueño", quien en 1573 proporciona una lista completa de los grupos sociales dentro del sistema de ceques del Cusco, como también de las panacas (familias reales) y otros grupos vinculados con la fiesta de la Situa (Citua). Esta última, narrada en las crónicas de Garcilaso de la Vega (2005 [1609]), Betanzos (1987 [1551]), Cristóbal de Molina (1947 [1573]) y Guamán Poma de Ayala (2008 [1615]), se conmemoraba durante el mes agosto (posiblemente septiembre), época del año que coincidía con el segundo paso del Sol por el anticenit (nadir) (Monteverde Sotil 2011). El objetivo de esta fiesta era expulsar el mal y las enfermedades del Cusco, e incluía rituales realizados en la plaza de haukaypata y el ushnu, con sacrificios al Sol y a las huacas - para propiciar el clima, la agricultura, el bienestar del Inca y su familia- mediante la utilización de antorchas encendidas durante las tres noches cercanas a la Luna llena del equinoccio (Maurtua 1906: 158-159). Para este mes lunar, según las crónicas, se reunían 400 guerreros en el centro de la ciudad, 100 mirando hacia cada dirección o suyu, iniciando la ceremonia cuando salía el sacerdote del templo del Sol, momento en que todos los guerreros gritaban "fuera el mal". Cada grupo 
de guerreros corría en la dirección de cada suyu, gritando la misma frase, hasta que llegaban a un punto convenido, donde eran relevados por grupos de mitimaes, hasta llegar a las afueras del Cusco en donde simbólicamente lanzaban las enfermedades y males a distintos cursos de agua (Zuidema 1995, 2011).

Por otro lado, trabajos arqueológicos realizados en Huánuco Pampa (Pino Matos 2005), Pumpu (Pasco) e Incahuasi en el Perú (Hyslop 1990), como así también en Viña del Cerro (Copiapó) en Chile y La Ciudacita (con plataforma ushnu) (Tucumán) en Argentina (Moyano 2010, 2014, 2018), son coherentes con el uso de ceques en contextos coloniales. Tal es el caso del centro histórico de Santiago de Chile, donde se han encontrado evidencias de un posible asentamiento incaico cercano a la Plaza de Armas (Cornejo \& Saavedra 2018), así como la utilización de los horizontes y la topografía local con fines calendáricos en fechas cercanas a los equinoccios y el crossover (Stehberg \& Sotomayor 2012, Moyano 2018). ${ }^{1}$

En la etnografía andina existen buenos ejemplos del uso de líneas o rumbos proyectados en el paisaje. Tal es el caso de las comunidades de Soras de Paria y Capinota, en el altiplano y valle de Cochabamba en Bolivia, donde información colonial temprana da cuenta de la existencia de mojones, a manera de marcadores de horizonte, para 42 rumbos imaginarios (24 para Paria y 18 para Capinota), relacionados con la organización del territorio y la población local. Esta configuración respetaría la base ortogonal y radial introducida por los incas, siguiendo la dirección este-oeste en el sentido contrario a las manecillas del reloj, coincidiendo en el mojón Llallagua que representa el primer punto del sistema Capinota y último punto de la serie Paria (Del Río 2005). Un caso similar corresponde al de la comunidad atacameña de Socaire, norte de Chile, donde durante la ceremonia de Limpia de Canales, de fines del mes de octubre, se invoca a un número cercano a 40 montañas de la región consideradas como responsables de las lluvias y el recurso hídrico (Barthel 1986). Esta ceremonia se realiza en las cercanías de la bocatoma del canal de la comunidad ( $5 \mathrm{~km}$ al E), en un centro ceremonial construido con rocas, utilizando botellas de chicha de algarrobo (aloja), siempre en dirección al este, a manera de lo que ha sido interpretado como un sistema de líneas sagradas con fines astronómicos (Mariscotti de Görlitz 1978, Tichy 1983, Moyano 2011). En este sentido, siguiendo a Zuidema (1989), quien realiza analogías entre el caso de Socaire y la ceremonia de la Situa en el Cusco, creemos que para identificar un sistema de ceques en El Shincal de Quimivil debiéramos encontrar los siguientes elementos:

- Uno o varios espacios (construidos o transformados), como por ejemplo el Coricancha o el ushnu en Cusco, de alto interés político, administrativo y ritual desde donde realizar todo tipo de actividades y observaciones.

- Una o varias líneas (imaginarias y no necesariamente rectas) que unan estos espacios con elementos significativos del paisaje (visibles entre sí o través de puntos intermedios), por ejemplo, cerros, rocas, quebradas, ríos, etc., considerados potencialmente sagrados o huacas.

- Que estos espacios y líneas tengan relación directa con la distribución espacial y arquitectónica del sitio, por ejemplo, cardinalidad, bipartición, jerarquía y secuencia, entre otros.

- Que estos espacios, líneas y divisiones espaciales se vean reflejados en los aspectos de la vida social del sitio (quizás lo más difícil de identificar), como por ejemplo residencia de las elites, lugares para reuniones y fiestas públicas, manejo del agua y producción agrícola, etcétera.

- Y por último, solo en el caso de la astronomía, que los elementos enumerados estén directamente relacionados, a través de marcadores de horizonte o cenitales, con fechas del calendario. En el caso de los incas, con las fiestas del Inti Raymi, Capac Raymi y la Situa, la observación de la Luna y estrellas, entre otras.

\section{EL SHINCAL DE QUIMIVIL: UNA CAPITAL INCA AL SUR DEL COLLASUYU}

El Shincal de Quimivil constituye uno de los lugares más emblemáticos de la presencia y poder de los incas en el Noroeste Argentino. Se encuentra a una altura de $1350 \mathrm{msnm}$ sobre el pie de monte del cerro Shincal en la localidad de Londres, Departamento de Belén, Provincia de Catamarca (coordenadas geográficas: $27^{\circ} 41^{\prime} 11,4^{\prime \prime}$ S, $67^{\circ} 10^{\prime} 42,9^{\prime \prime} \mathrm{O}$ ). Su paisaje presenta características muy particulares enmarcadas por cerros y cursos de agua dentro de un bosque abierto espinoso donde dominan algarrobos, chañares, acacias, talas y shinquis. Hacia el este y el oeste del sitio se encuentran dos ríos importantes, el Hondo y el Quimivil, respectivamente, que delimitan de alguna manera su espacio principal. 
Este último es al mismo tiempo atravesado de noroeste a sureste por otro curso, el arroyo Simbolar, que une los anteriores, generando naturalmente un espacio dividido en dos partes.

El espacio urbano se compone de diferentes conjuntos arquitectónicos que responden a la idea de kancha o Recinto Perimetral Compuesto (RPC). Posee una plaza o haukaypata, con un ushnu o plataforma ceremonial cuadrangular, una kallanka y un muro de cuatro vanos en su interior. En los alrededores de esta plaza existen diversos conjuntos habitacionales kancha-algunas con sus respectivas kallanka-, recintos kancha para actividades rituales (kancha-templo), unidades de almacenamiento (qollqa) y segmentos de Qhapaq Ñan claramente visibles sobre la ladera sureste del cerro Shincal. Esta planificación presenta una orientación este-oeste y norte-sur, que se articula con determinados referentes o marcadores geográficos y culturales visibles, como los cerros de los alrededores. Estos cerros responden a diversos topónimos $\mathrm{y}$ forman parte del paisaje humanizado y sacralizado del sitio; y de acuerdo a la distancia que tienen con la haukaypata pueden formar parte del entorno más adyacente o más alejado. En las proximidades están el cerro del Intihuatana (también conocido como Cerrito Norte) al norte, el cerro Loma Larga (o cerro de La Cruz) al sur, el cerro Aterrazado Occidental (CAOcc.) al oeste, el cerro Aterrazado Oriental (CAOr.) al este, el cerro Shincal (el más alto, $2305 \mathrm{msnm}$, domina el paisaje regional cual cerro tutelar) al noroeste, el cerro Divisadero al suroeste y el cerro Indio Dormido al sureste (fig. 3).

A su vez, se encuentran los cerros que forman parte del horizonte topográfico lejano del sitio y que, de acuerdo a nuestros relevamientos, se los conoce como: el cerro Agua de los Molles (fácilmente reconocido por su forma en punta) en el horizonte oriental, y el cerro de La Reina en el horizonte occidental.

En los cerros más inmediatos del sitio hemos encontrado evidencias de intervención antrópica (Moralejo 2011). Con respecto a los del entorno lejano, aún se desconoce si poseen restos culturales, aunque se encuentran próximos a ser explorados a partir de las nuevas tecnologías de información geográfica que estamos utilizando.

La gran plaza o haukaypata es cuadrangular, con $175 \mathrm{~m}$ de lado, y está prácticamente orientada a los puntos cardinales, ${ }^{2}$ conformando ejes de orientación con el cerro del Intihuatana, los cerros aterrazados Oriental y Occidental y la Loma Larga. En su centro

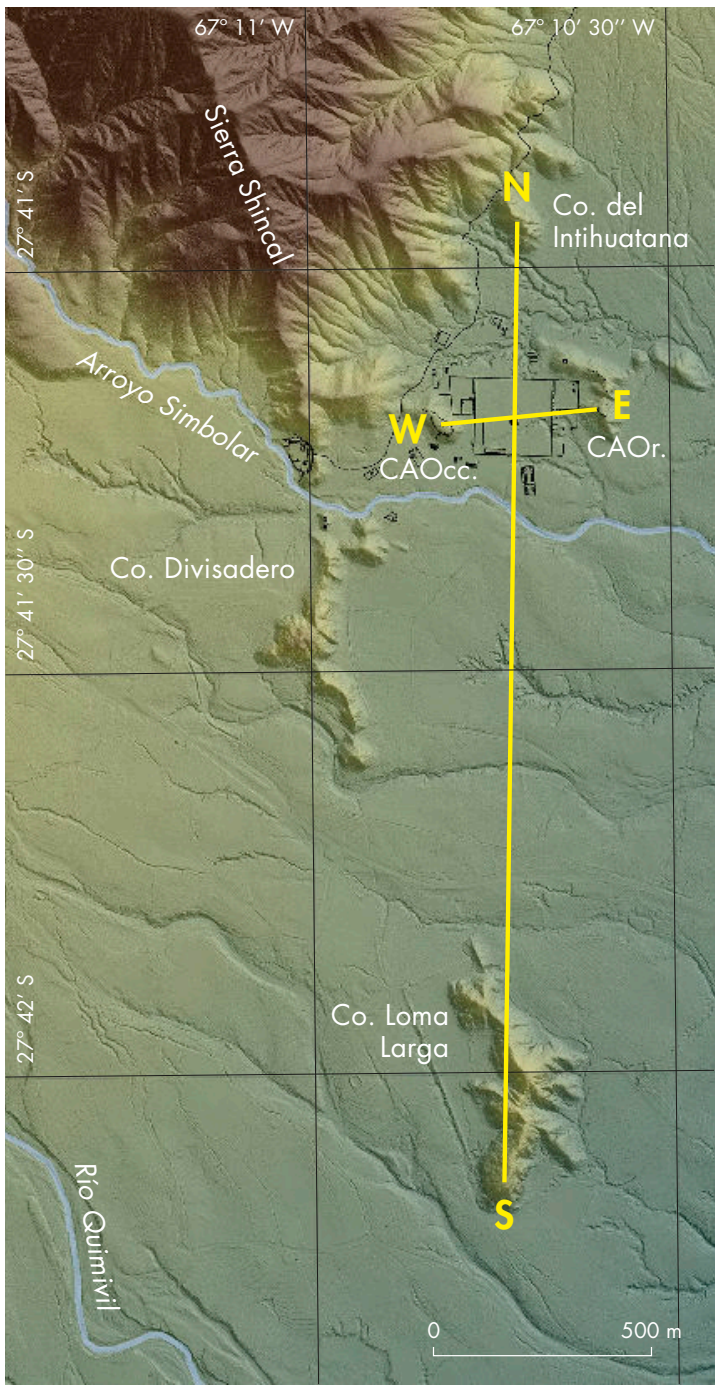

Figura 3. Modelo Digital del Terreno donde se pueden observar los cerros mencionados correspondientes al entorno más cercano del sitio y la relación cardinal entre ellos. Figure 3. Digital Elevation Model in which it is possible to observe the hills mentioned closest to the site and the cardinal relation between them.

se encuentra la plataforma ushnu con una escalinata orientada hacia el oeste a unos $265^{\circ}$ (magnético) o $264^{\circ} 38^{\prime}$ (corregido) (Farrington 1999, Farrington et al. 2015). ${ }^{3}$ Este espacio central del sitio, que incluye tanto la plaza propiamente dicha como la plataforma, habría sido lugar de diversas ceremonias, como por ejemplo el Inti Raymi, y actividades públicas, como el trueque o catu, organizadas por la élite local (Raffino et al. 2020).

El trazado cardinal alrededor de la plaza, en directa relación con los cerros mencionados más arriba, 


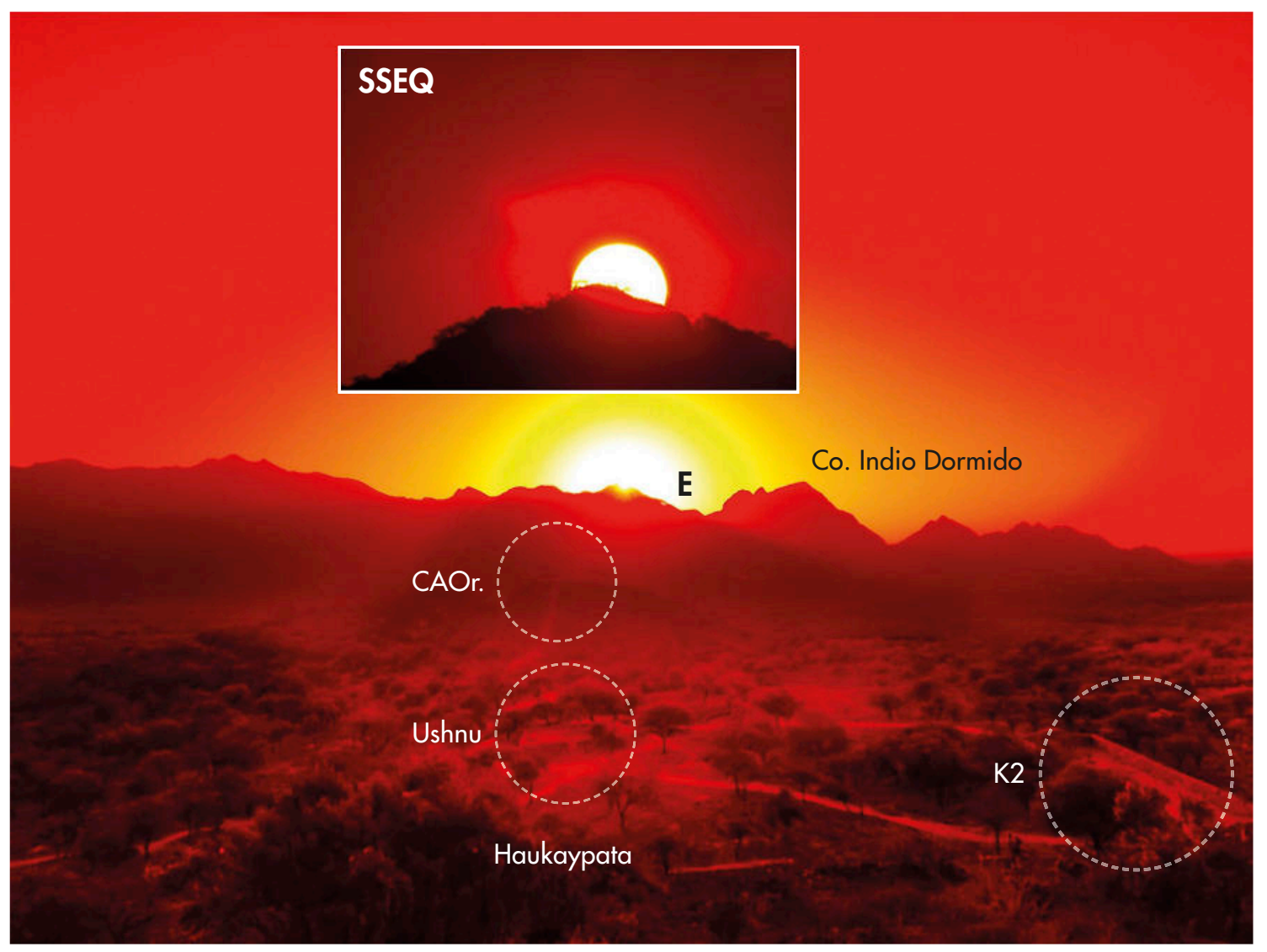

Figura 4. Salida del Sol en el equinoccio de septiembre (22/ 09/ 16). Vista desde el CAOcc. (Fotografía: R. Moyano). Figure 4. Sunrise on the September equinox (09/22/16). View from the CAOcc. (Photograph: R. Moyano).

acentúa aún más la posición central del ushnu. Como bien mencionamos, hacia los flancos este y oeste de la plaza se encuentran los cerros aterrazados Oriental y Occidental. Este eje marca las salidas y las puestas del Sol en momentos cercanos a los equinoccios (Farrington et al. 2015, Corrado et al. 2018) (fig. 4).

Ambos cerros presentan su cima aplanada y aterrazada con un muro de contención. El acceso al Aterrazado Oriental (altura de $1403 \mathrm{msnm}$ ) se realiza por la ladera oeste a través de una escalinata de piedra (103 escalones) ancha y recta. En su cima son claramente visibles los restos de un semicírculo de rocas.

El camino al Aterrazado Occidental (altura de $1405 \mathrm{msnm}$ ) se hace a través de una escalinata angosta dispuesta en zigzag sobre la ladera suroeste. En su cima es posible observar varios afloramientos de granito que representan un conjunto de rocas wak' as (huacas). Una de ellas, ubicada hacia el norte, tiene características muy particulares: posee dos grandes fisuras y tres oquedades artificiales (de $20 \mathrm{~cm}$ de diámetro y $20 \mathrm{~cm}$ de profundidad) (fig. 5). Este conjunto de fisuras y oquedades podrían estar simbolizando la idea de paqcha, la misma que se tiene para el ushnu, cuando pensamos en la acumulación de agua (oquedades) que corre entre las rocas (fisuras) y se vierte sobre la tierra (pachamama) (Matos 1999). Otra de las posibles funcionalidades de estas oquedades estaría relacionada con la entrega de ofrendas, la elevación de un mástil o la observación del cielo cuando está colmado de agua (Farrington et al. 2015). Otro de los afloramientos, localizado en el centro de la cima, presenta un perfil aparentemente natural que se asemeja a la línea de cerros del horizonte oeste-noroeste. Recientemente, debido a la constante erosión de la cima, se han descubierto dos alineaciones de rocas, que según las interpretaciones estarían marcando fechas astronómicas como el 21 de junio (solsticio de invierno) y la salida del Sol para los 

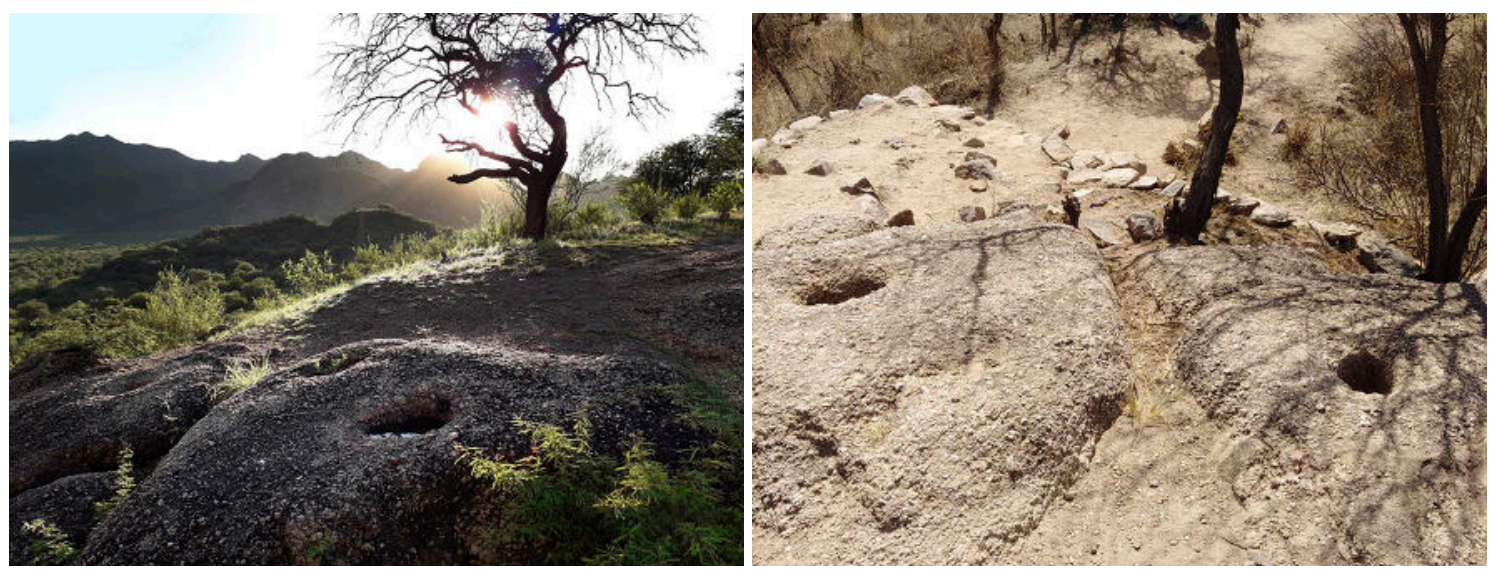

Figura 5. Afloramiento de granito en el Cerro Aterrazado Occidental con presencia de oquedades y fisuras. (Fotografías realizadas desde diferentes ángulos. Izquierda: R. Moyano. Derecha: R. A. Moralejo). Figure 5. Granite outcropping on Cerro Aterrazado Occidental with cavities and cracks. (Photographs taken from different angles. Left: R. Moyano. Right: R. A. Moralejo).

días 13 de febrero y 28 de octubre, momentos en que ocurriría el paso del Sol por el cenit en Cusco (Lynch \& Giovannetti 2018; Corrado \& Giménez Benítez 2019). No obstante, tal como plantea Zuidema (2011), y a partir de tablas astronómicas corregidas, el paso del Sol por el cenit en el Cusco ocurriría los días 12 de febrero y 29 de octubre, +/- 1 día (fig. 6).

Hacia el norte de la plaza, sobre la cima del cerro del Intihuatana (altura de $1421 \mathrm{msnm}$ ), Farrington (1999) señala la existencia de una roca (tipo gnomon), de $21 \mathrm{~cm}$ de altura y $30 \mathrm{~cm}$ de diámetro, tallada sobre una laja de granito rosado, a la cual se accede a través de una escalinata. Desde el ushnu, se ubica a una distancia de $468 \mathrm{~m}$ y una orientación de $4^{\circ}$, lo que indicaría casi una perfecta alineación norte-sur de ambos rasgos. De acuerdo con la hipótesis del investigador, podría tener una función relacionada con el ritual y la observación astronómica. En trabajos de campo posteriores hemos corroborado la presencia de esta roca junto con otros elementos a lo largo de la cima, como estructuras circulares de piedra, conjuntos de grandes rocas delimitando espacios internos y oquedades rituales sobre bloques de granito (Moralejo 2011). ${ }^{4}$ A ello debemos sumar la cercanía del Camino del Inca o Qhapaq Nan que circula a través del Abra del Intihuatana con dirección noreste-suroeste. Vale destacar también que la acción antrópica y animal, junto con la erosión natural, han deteriorado gran parte de la cima de este cerro, afectando en gran medida la escalinata, el posible Intihuatana y las estructuras circulares.

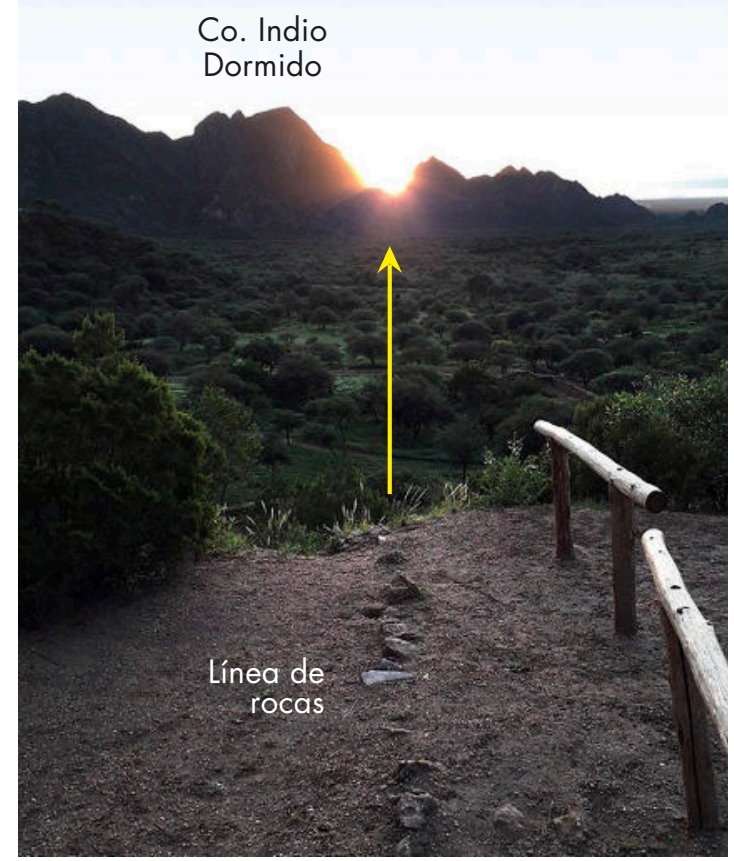

Figura 6. Salida del Sol desde el Cerro Aterrazado Occidental (13/ 02/ 19). (Fotografía: R. Moyano). Figure 6. Sunrise from Cerro Aterrazado Occidental (02/13/19). (Photograph: R. Moyano).

Hacia el sur de la plaza, a una distancia de 1,5 $\mathrm{km}$, se encuentra el cerro Loma Larga (altura de 1431 $\mathrm{msnm}$ ), cuya cima presenta nivelaciones y su ladera está rodeada por muros de contención. A lo largo del cerro existen restos de estructuras, cerámica Aguada del 
período Medio (400-950/1000 DC) y Belén del período Tardío del Noroeste Argentino (950/1000-1420/1430 DC), y una oquedad labrada sobre la superficie (Couso et al. 2013). Al pie del cerro, en el lado suroeste, existe una cueva conocida localmente como la Salamanca (Farrington 1999, Moralejo 2011, Farrington et al. 2015). Finalmente, a una distancia de 698 metros hacia el suroeste de la plaza se encuentra el cerro Divisadero (1458 msnm), en cuya superficie irregular de la cima, con una amplia visibilidad hacia el entorno, también se han detectado oquedades similares a las ya mencionadas (Moralejo 2011, Giovannetti 2016).

Estos datos permiten demostrar que el ushnu y la plaza articularon un paisaje sagrado que estaba compuesto por diversos elementos naturales y lugares pensados y construidos por los incas. La presencia de tres cursos de agua junto a la red vial le otorgaba un significado particular al paisaje, vinculado con la idea de encuentro, o tinkuy, que era considerado sagrado. Esta red de marcadores espaciales geográficos y culturales conformaba un modelo social del paisaje, con determinadas simetrías y regularidades urbanísticas cuidadosamente planificadas, como en otros sitios incaicos de los Andes centrales. Ello fue lo que condujo a pensar que El Shincal de Quimivil podría replicar simbólicamente la capital del Tawantinsuyu, razón por la cual se le dio el carácter de "Nuevo Cusco" (Raffino et al. 1982, Farrington 1999).

\section{METODOLOGÍA}

La metodología incluyó la observación y registro in situ de los solsticios y equinoccios (entre los años 2012 y 2016), además de una visita en febrero de 2019 para el estudio del ushnu, los cerros aterrazados Oriental y Occidental (datos ya publicados en 2013 y 2015), la plaza o haukaypata, la kancha 5f, el sector del gnomon o Intihuatana -identificado por Farrington (1999) - y el cerro Loma Larga (datos inéditos). ${ }^{5}$ Esta tarea tuvo como finalidad identificar al menos 20 puntos astronómicos mediante las observaciones de horizonte, el cálculo geodésico y la fotografía en $360^{\circ} .{ }^{6}$ Con un GPS (Garmin E-trex) se obtuvieron las coordenadas geográficas del lugar (latitud, longitud y altura ortométrica, Datum wGS 84). Con ayuda de un tránsito mecánico (Luft BD-3, resolución angular de 1') se obtuvieron lecturas verticales y azimutales de los horizontes, verificadas luego con cartografía, brújula y clisímetro óptico (precisión angular de $\pm 0,5^{\circ}$ con resolución de $\left.1^{\circ}\right)$, rectificando la declinación magnética (modelo wмм 2014-2019, NOAA). ${ }^{7}$ En laboratorio -como método exploratoriose utilizaron imágenes Google Earth Pro y Peak Finder para proyecciones de luz y sombra en el análisis de cuencas visuales y fechas astronómicas. ${ }^{8}$ Además, se obtuvieron valores corregidos mediante el levantamiento topográfico realizado en 2016 con tecnología LIDAR (Light Detection and Ranging) gracias a un convenio científico y tecnológico de colaboración institucional (Moralejo et al. 2018).

Los valores de azimut y declinación del entorno se obtuvieron con un sistema de referencia de horizonte ( \pm 1 día), junto con la tabla de cálculo Hansómetro (Martz de la Vega et al. 2013), a partir de la formula básica de cálculo en arqueoastronomía (Aveni 2005: 166). ${ }^{9}$ Para el análisis astronómico se utilizó el software Stellarium 0.19.3, Starcalc 5.72 y Moshier's Ephemeris Program 5.1, tomando en cuenta siempre los factores de refracción atmosférica, paralaje y curvatura de la Tierra (Šprajc 2001), junto con información proporcionada por el Instytut Geodezji i Kartografii (IGiK, Polonia) y la NASA para datos de fechas (como eclipses) y declinación. ${ }^{10}$ De forma complementaria, se construyó una montea lunisolar, junto con una fotografía panorámica del horizonte $\left(360^{\circ} / 21.600\right.$ pixeles) (Moyano 2018), para ilustrar los eventos y marcadores astronómicos identificados. Estos últimos fueron posteriormente transferidos a la imagen satelital mediante el editor de imágenes Adobe Photoshop. ${ }^{11}$

\section{ARQUEOASTRONOMÍA EN EL SHINCAL DE QUIMIVIL}

En un principio, las observaciones realizadas desde la plataforma ushnu y los cerros aterrazados del este y oeste (CAOr. y CAOcc.) apuntaban a la utilización de los horizontes oriental y occidental para la observación y el seguimiento de la Luna, los fenómenos de eclipses y la salida del Sol en el solsticio de diciembre. Ello condujo a pensar en el espacio central de El Shincal, como un lugar destinado a ritos de fertilidad, del agua y de los cerros, de acuerdo con los modelos cusqueños de manejo y apropiación de los espacios (Moyano et al. 2015) (fig. 7). Por ejemplo, desde el ushnu fue posible determinar la posición de la salida de la Luna llena cercana a su parada menor al norte (sLMN) (az.: 63 15 , alt.: $08^{\circ} 14^{\prime}$, 


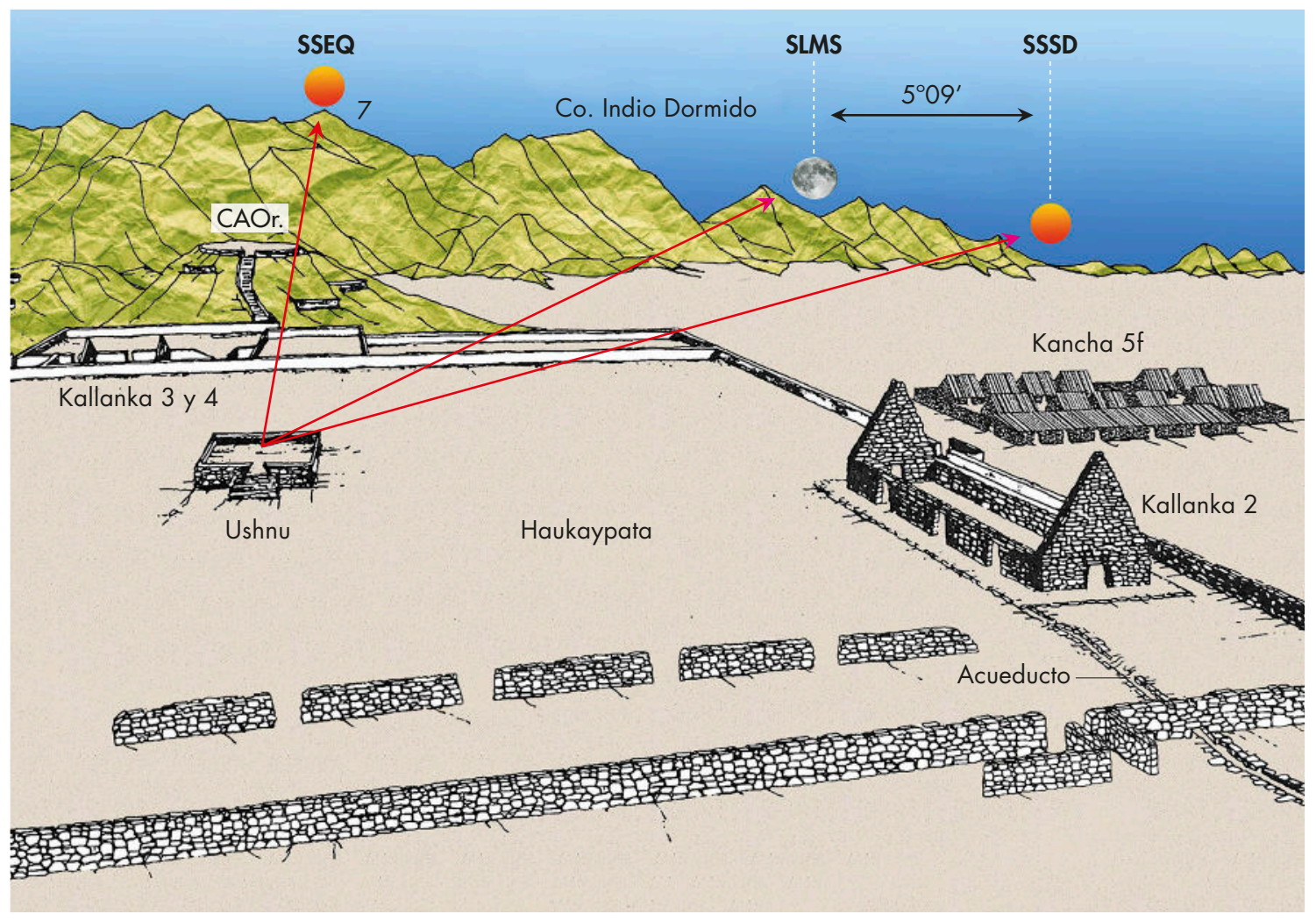

Figura 7. Horizonte E de El Shincal de Quimivil visto desde el Cerro Aterrazado Occidental. Figure 7. E horizon of El Shincal de Quimivil viewed from Cerro Aterrazado Occidental.

$\left.\delta:+19^{\circ} 07^{\prime}, \delta(\mathrm{PL}):+18^{\circ} 36^{\prime}\right)$, que bien pudo relacionarse con un par de eclipses (parciales) visibles, distantes uno del otro a 54 años, las noches del 15-16 de noviembre de 1491 y el 18 de diciembre de 1545 (Saros 127). ${ }^{12}$ En ambos casos, se tuvo como punto de referencia la posición del Sol en el solsticio opuesto, es decir junio. Aún más interesante resulta el hecho de que ocurran las paradas menores de la Luna al sur (SLMS) en un sector conocido como cerro Indio Dormido (az.: $109^{\circ} 38^{\prime}$, alt.: $\left.00^{\circ} 38^{\prime}, \delta:-17^{\circ} 37^{\prime}, \delta(\mathrm{PL}):-18^{\circ} 04^{\prime}\right)$, marcador que además pudo relacionarse con otro grupo de eclipses: los ocurridos en las madrugadas de los días 24 de julio de 1469 y 26 de agosto de 1523 (Saros 120); y los eclipses totales ocurridos el 2-3 de mayo de 1482 y el 4 de junio de 1536 (Saros 103) (fig. 8).

Desde el mismo ushnu, pero al poniente, se destaca en el horizonte la orientación $272^{\circ} 48^{\prime}$ (alt: $09^{\circ} 35^{\prime}, \delta$ : $-01^{\circ}$ $\left.59^{\prime}\right)$ en el cerro de La Reina, con la puesta del Sol para los días 15 de marzo y 27 de septiembre, fechas cercanas a los equinoccios (P-PSEQ). Este fenómeno pudo estar relacionado con el crossover andino o posición promedio de la Luna llena cercana a la línea este-oeste (Moyano 2018). La misma orientación tiene la kallanka 2 (K2) ubicada al sur de la plaza o haukaypata. Esta kallanka, si bien se encuentra totalmente restaurada, mantiene una orientación este-oeste (tabla 1) posiblemente relacionada con la ceremonia de la Situa y el inicio de la primavera en los Andes del Collasuyu (Moyano 2018) (fig. 9).

Durante los años 2012 a 2016 realizamos observaciones in situ desde el cerro Aterrazado Occidental con el objetivo de corroborar la salida del Sol en el solsticio de diciembre y postular, a partir de trabajos previos, la existencia de otros puntos de observación además del ushnu. Para ello se asumió la importancia de la cuatripartición del enclave en el eje este-oeste (cerro Aterrazado Oriental/cerro Aterrazado Occidental) y norte-sur (cerro del Intihuatana/cerro Loma Larga), tal cual ya lo había advertido Farrington (1999). Otros ejemplos de sitios Inca que presentan la división en cuatro, son el mismo Cusco, Quito y Huánuco Pampa, donde 
the illedpse cafic nara goviocipsetter!

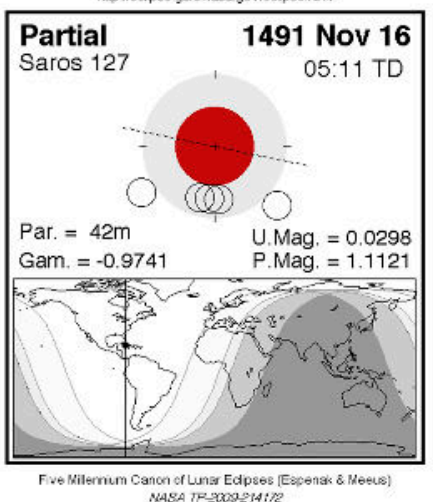

Ine Abchpse. gstc nasa goviosibee htm

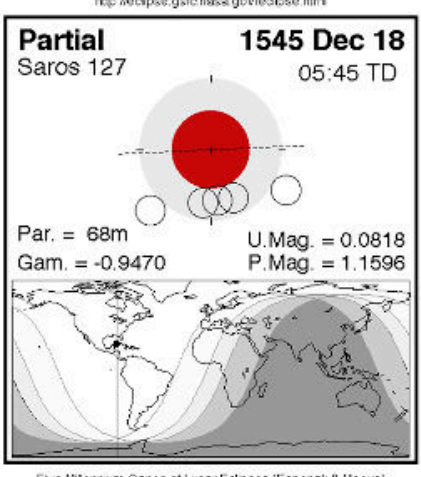

Five Silemum Canon of Lung Edpses (Espenak \& Weeus]
Htpilieclipac grforasa poviediose htm.

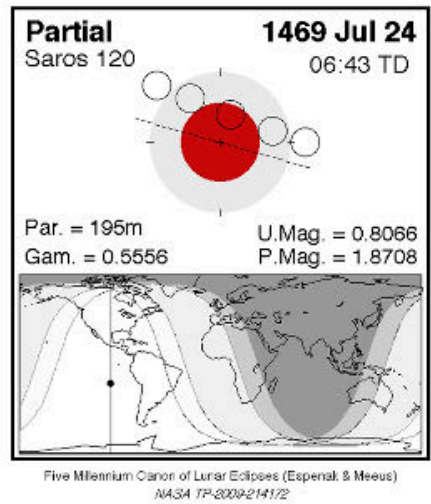

htip: itocipese gsfarasa goveqdipsehtm

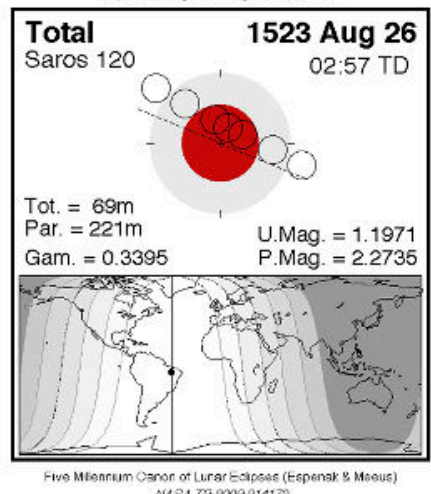

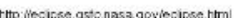

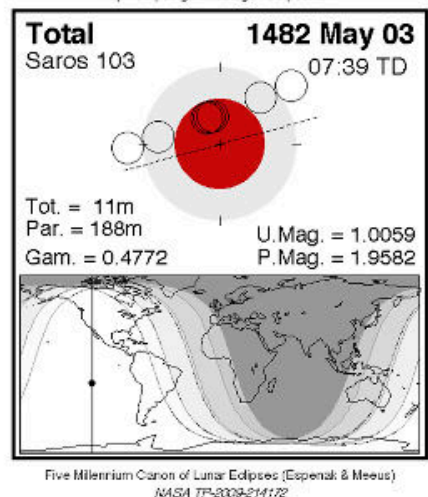

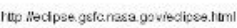

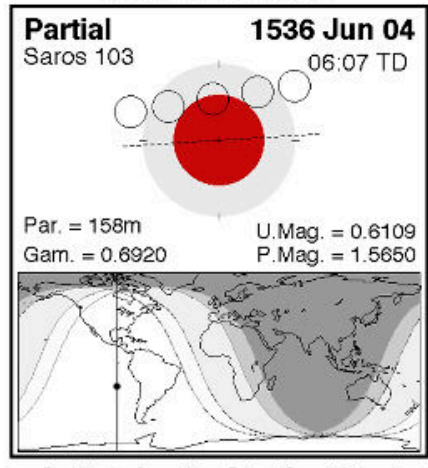

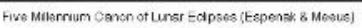

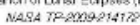

Figura 8. Eclipses de Luna: Saros 127, 120 y 103. Figure 8. Lunar eclipses: Saros 127, 120, and 103.

inclusive se plantea una direccionalidad y jerarquía de cada suyu con fines astronómicos y paisajísticos (Pino Matos 2005, Zuidema 2011). En este caso, se confirmó la posibilidad de seguir el solsticio de diciembre desde el Intihuatana (por las estribaciones del este), aun cuando es difícil actualmente identificar el elemento lítico debido al maltrato por la acción antrópica (ganado caprino) y las inclemencias del tiempo (fig. 10).

De igual manera, desde el cerro Loma Larga (sector donde se encuentra la oquedad) se lograron datos sugerentes con respecto a los horizontes oriental y occidental. Estos resultados confirman la utilización del paisaje con fines culturales como, por ejemplo, fechas de solsticios, equinoccios y lunisticios, entre otros. Se destacan puntos cercanos a la salida del Sol en los equinoccios (P-SSEQ) con valores de declinación de (+)04 $37^{\prime}$ y (-)00 55', es decir, para los días 01 abr/11-12 sep y 18 mar/25 sep (tabla 2: puntos 9 y 10), lo cual es altamente congruente con el comportamiento general del sitio y otros asentamientos incaicos (fig. 11).
La información recientemente obtenida de la haukaypata -tanto de los muros que la delimitan como del muro de cuatro vanos de su interior- y de la kancha $5 f$ asumen lógicas internas muy similares en orientación, declinación y fecha solar cercana a los equinoccios. Primero, en la haukaypata los muros este y oeste presentan entre $01^{\circ}$ y $01^{\circ} 30^{\prime}$ de desviación con respecto al norte, mientras los muros norte y sur tienen azimuts promedios de $92^{\circ}$ y $272^{\circ}$, es decir, con esquinas no necesariamente a $90^{\circ}$, marcando las fechas del 11 de marzo y 01 de octubre al oriente, y las fechas del 13-14 de marzo y 29 de septiembre al poniente (tabla 3 y fig. 12).

Segundo, la disposición del muro interno de cuatro vanos, ubicado en el sector suroeste del interior de la haukaypata, orienta sus cuatro vanos en sentido este-oeste a las salidas del Sol los días 12 de marzo y 01 de octubre (azimut: 91 54'), lo cual es altamente significativo, debido a que coincide con la orientación del lugar y otros sitios del Collasuyu (Moyano 2018) (tabla 4 y fig.13). 
Memoria de cálculo kallanka 2

Fecha: 22/ 12/ 15

$\delta$ (lat): $27^{\circ} 41^{\prime} 13.69^{\prime \prime} \mathrm{S}$ $\lambda$ (lon): $67^{\circ} 10^{\prime} 44.52^{\prime \prime} \mathrm{W}$ Altitud: $1354 \mathrm{msm}$

(GMT-3)

$\mathrm{TT}=13.958889$

Et Obs $=11.97787342$

$\delta$ Obs $=-23.43533198$

LHA $=-37.4642181$

$\mathrm{HaCalc}=56.0644370$

$\mathrm{AaCal}=91.41592085$
Tabla 1. Cálculo correspondiente a kallanka 2. Table 1. Calculation corresponding to kallanka 2.

\begin{tabular}{c|c|c|c|c|c|c}
\hline $\begin{array}{c}\text { PUNTO/NOMBRE } \\
\begin{array}{c}\text { Reina }) \\
\text { Co. Le La CALC. }\end{array}\end{array}$ & ALT. CALC. & DEC. CALC. & FECHA & DEC. (PL) & OBS. \\
\hline 3 & $93^{\circ} 01^{\prime} 05^{\prime}$ & $09^{\circ} 46^{\prime}$ & $(-) 01^{\circ} 50^{\prime}$ & $15-16 \mathrm{mar} / 27 \mathrm{sep}$ & $(-) 02^{\circ} 16^{\prime}$ & P-PSEQ \\
\hline 4 & $93^{\circ} 51^{\prime}$ & $04^{\circ} 58^{\prime}$ & $(-) 05^{\circ} 39^{\prime}$ & $06 \mathrm{mar} / 07 \mathrm{oct}$ & $(-) 06^{\circ} 05^{\prime}$ & P-SSEQ \\
\hline 5 & $97^{\circ} 53^{\prime}$ & $05^{\circ} 07^{\prime}$ & $(-) 09^{\circ} 17^{\prime}$ & $24 \mathrm{feb} / 17 \mathrm{oct}$ & $(-) 09^{\circ} 43^{\prime}$ & n/a \\
\hline
\end{tabular}

\section{CARTA LUNI-SOLAR EL SHINCAL (USHNU)}

\section{CERRO DEL INTIHUATANA}

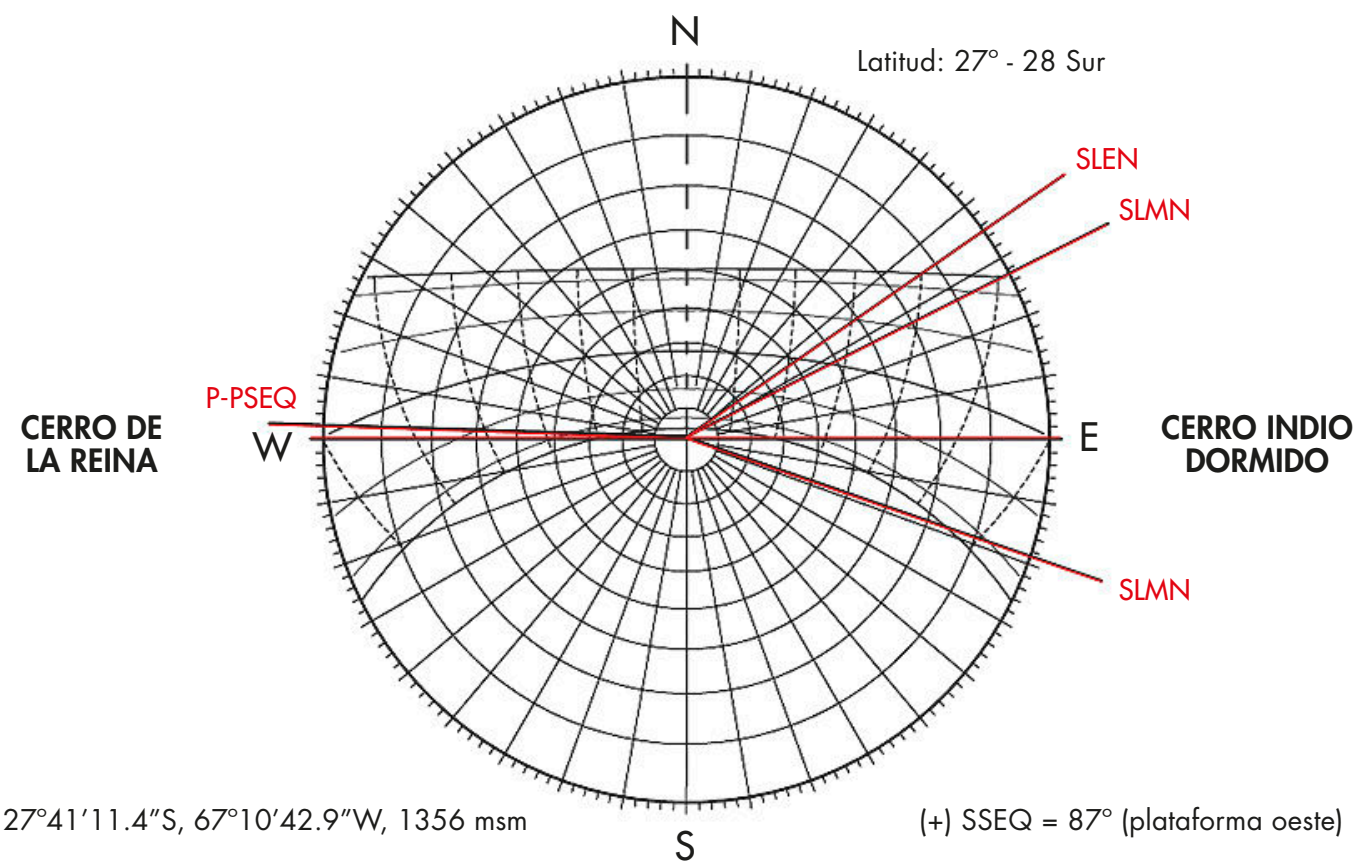

CERRO LOMA LARGA

Figura 9. Montea luni-solar de El Shincal. Figure 9. Luni-solar diagram of El Shincal. 

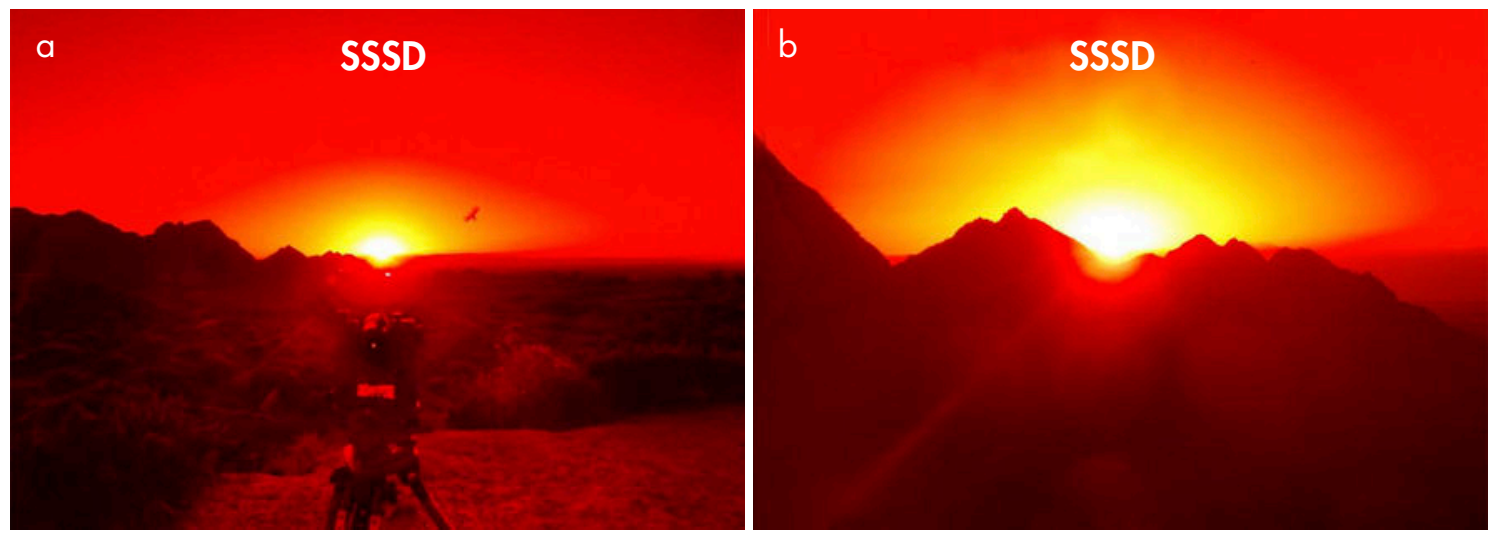

Figura 10. Salida Sol solsticio diciembre (sssD) desde Cerro Aterrazado Occidental (a) e Intihuatana (b), año 2015 (Fotografías: R. Moyano). Figure 10. Sunrise on the December solstice (SSSD) from Cerro Aterrazado Occidental (a) and Intihuatana (b), year 2015 (Photographs: R. Moyano).

\section{Memoria de cálculo Loma Larga}

Fecha: $21 / 12 / 15$

$\delta$ (lat): $27^{\circ} 42^{\prime} 07.6^{\prime \prime} \mathrm{S}$

$\lambda$ (lon): $67^{\circ} 10^{\prime} 43.9^{\prime \prime} \mathrm{W}$

Altitud: $1376 \mathrm{msnm}$

\section{(GMT-3)}

$\mathrm{TT}=19.633056$

Et Obs $=11.97156086$

$\delta$ Obs $=-23.43556385$

LHA $=47.7431430$

$\mathrm{HaCalc}=46.9829872$

$\mathrm{AaCal}=264.5065471$
Tabla 2. Cálculo correspondiente a Loma Larga. Table 2. Calculation corresponding to Loma Larga.

\begin{tabular}{c|c|c|c|c|c|c}
\hline $\begin{array}{c}\text { PUNTO/NOMBRE } \\
\begin{array}{c}\text { (Co. Agua de } \\
\text { los Molles) }\end{array}\end{array}$ & $28^{\circ} 46^{\prime}$ & $06^{\circ} 33^{\prime}$ & $(+) 45^{\circ} 58^{\prime} 19.8^{\prime \prime}$ & $\mathrm{n} / \mathrm{a}$ & $(+) 45^{\circ} 13^{\prime}$ & $\mathrm{n} / \mathrm{a}$ \\
\hline 2 & & & & & & \\
\hline 3 & $43^{\circ} 42^{\prime}$ & $06^{\circ} 00^{\prime}$ & $(+) 36^{\circ} 05^{\prime}$ & $\mathrm{n} / \mathrm{a}$ & $(+) 35^{\circ} 28^{\prime}$ & $\mathrm{n} / \mathrm{a}$ \\
\hline 4 & $45^{\circ} 04^{\prime}$ & $05^{\circ} 50^{\prime}$ & $(+) 35^{\circ} 09^{\prime}$ & $\mathrm{n} / \mathrm{a}$ & $(+) 34^{\circ} 32^{\prime}$ & $\mathrm{n} / \mathrm{a}$ \\
\hline 5 & $62^{\circ} 46^{\prime}$ & $02^{\circ} 29^{\prime}$ & $(+) 22^{\circ} 43^{\prime}$ & $06-07 \mathrm{jun} / 06 \mathrm{jul}$ & $(+) 22^{\circ} 14^{\prime}$ & $\mathrm{n} / \mathrm{a}$ \\
\hline 6 & $66^{\circ} 15^{\prime}$ & $03^{\circ} 25^{\prime}$ & $(+) 19^{\circ} 15^{\prime}$ & $16-17 \mathrm{may} / 27-28 \mathrm{jul}$ & $(+) 18^{\circ} 46^{\prime}$ & SLMN \\
\hline 7 & $67^{\circ} 31^{\prime}$ & $03^{\circ} 45^{\prime}$ & $(+) 17^{\circ} 59^{\prime}$ & $11 \mathrm{may} / 02 \mathrm{ago}$ & $(+) 17^{\circ} 29^{\prime}$ & $\mathrm{n} / \mathrm{a}$ \\
\hline 8 & $78^{\circ} 39^{\prime}$ & $00^{\circ} 24^{\prime}$ & $(+) 08^{\circ} 30^{\prime}$ & $11 \mathrm{abr} / 01 \mathrm{sep}$ & $(+) 08^{\circ} 03^{\prime}$ & $\mathrm{n} / \mathrm{a}$ \\
\hline 10 & $80^{\circ} 43^{\prime}$ & $01^{\circ} 53^{\prime}$ & $(+) 07^{\circ} 26^{\prime}$ & $08 \mathrm{abr} / 04 \mathrm{sep}$ & $(+) 06^{\circ} 59^{\prime}$ & $\mathrm{n} / \mathrm{a}$ \\
\hline 11 & $84^{\circ} 25^{\prime}$ & $01^{\circ} 00^{\prime}$ & $(+) 04^{\circ} 37^{\prime}$ & $01 \mathrm{abr} / 11-12 \mathrm{sep}$ & $(+) 04^{\circ} 11^{\prime}$ & $\mathrm{P}-\mathrm{SSEQ}$ \\
\hline 12 & $91^{\circ} 07^{\prime}$ & $00^{\circ} 18^{\prime}$ & $(-) 00^{\circ} 55^{\prime}$ & $18 \mathrm{mar} / 25 \mathrm{sep}$ & $(-) 01^{\circ} 22^{\prime}$ & $\mathrm{P}-\mathrm{SSEQ}$ \\
\hline 13 (Co. de La Reina) & $260^{\circ} 18^{\prime}$ & $08^{\circ} 08^{\prime}$ & $(-) 12^{\circ} 16^{\prime}$ & $16 \mathrm{feb} / 26 \mathrm{oct}$ & $(-) 12^{\circ} 42^{\prime}$ & $\mathrm{n} / \mathrm{a}$ \\
\hline 14 & $262^{\circ} 42^{\prime}$ & $08^{\circ} 37^{\prime \prime}$ & $(-) 10^{\circ} 22^{\prime}$ & $21-22 \mathrm{feb} / 21 \mathrm{oct}$ & $(-) 10^{\circ} 48^{\prime}$ & $\mathrm{n} / \mathrm{a}$ \\
\hline 15 & $265^{\circ} 17^{\prime}$ & $08^{\circ} 55^{\prime}$ & $(-) 09^{\circ} 57^{\prime}$ & $22-23 \mathrm{feb} / 29 \mathrm{oct}$ & $(-) 10^{\circ} 22^{\prime}$ & $\mathrm{n} / \mathrm{a}$ \\
\hline & $248^{\circ} 46^{\prime}$ & $07^{\circ} 30^{\prime}$ & $(-) 07^{\circ} 57^{\prime}$ & $28 \mathrm{feb} / 14 \mathrm{oct}$ & $(-) 08^{\circ} 22^{\prime}$ & $\mathrm{n} / \mathrm{a}$ \\
\hline
\end{tabular}

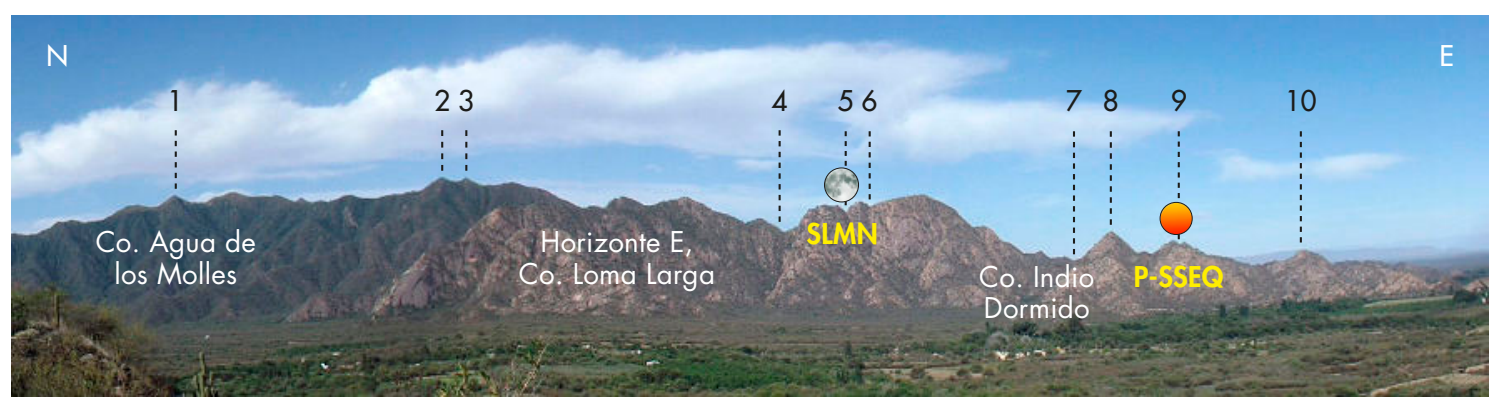

Figura 11. Horizonte E, cerro Loma Larga. (Fotografía: R. Moyano). Figure 11. E horizon, hill Loma Larga. (Photograph: R. Moyano). 
Tabla 3. Valores calculados correspondientes a la haukaypata de El Shincal. Los valores fueron obtenidos con brújula y clisímetro, y posteriormente corregidos con la calculadora de declinación magnética y la plataforma Peak Finder. Table 3. Calculated values corresponding to the haukaypata of El Shincal. The values were obtained with compass and clysimeter and subsequently corrected with magnetic declination calculator and Peak Finder platform.

\begin{tabular}{c|c|c|c|c|c|c} 
MURO & AZ. CALC. & ALT. CALC. & DEC. CALC. & FECHA & DEC. (PL) & OBS \\
Norte (vista al E) & $92^{\circ}$ & $03^{\circ} 48^{\prime}$ & $(-) 03^{\circ} 26^{\prime}$ & $11 \mathrm{mar} / 01 \mathrm{oct}$ & $(-) 03^{\circ} 52^{\prime}$ & P-SSEQ \\
\hline Norte (vista al W) & $272^{\circ}$ & $09^{\circ} 30^{\prime}$ & $(-) 02^{\circ} 36^{\prime}$ & $14 \mathrm{mar} / 29 \mathrm{sep}$ & $(-) 03^{\circ} 02^{\prime}$ & P-PSEQ (Co. de La Reina) \\
\hline Sur (vista al E) & $92^{\circ}$ & $03^{\circ} 54^{\prime}$ & $(-) 03^{\circ} 29^{\prime}$ & $11 \mathrm{mar} / 01 \mathrm{oct}$ & $(-) 03^{\circ} 55^{\prime}$ & P-SSEQ \\
\hline Sur (vista al W) & $272^{\circ}$ & $09^{\circ} 24^{\prime}$ & $(-) 02^{\circ} 33^{\prime}$ & $13-14 \mathrm{mar} / 29 \mathrm{sep}$ & $(-) 02^{\circ} 59^{\prime}$ & P-PSEQ (Co. de La Reina) \\
\hline Este (vista al N) & $01^{\circ} 30^{\prime}$ & $07^{\circ} 30^{\prime}$ & $(+) 54^{\circ} 53^{\prime}$ & $\mathrm{n} / \mathrm{a}$ & $\mathrm{n} / \mathrm{a}$ & $\mathrm{n} / \mathrm{a}$ \\
\hline Este (vista al S) & $181^{\circ} 30^{\prime}$ & $00^{\circ} 42^{\prime}$ & $(-) 61^{\circ} 41^{\prime}$ & $\mathrm{n} / \mathrm{a}$ & $\mathrm{n} / \mathrm{a}$ & $\mathrm{n} / \mathrm{a}$ \\
\hline Oeste (vista al N) & $01^{\circ}$ & $08^{\circ} 36^{\prime}$ & $(+) 53^{\circ} 48^{\prime}$ & $\mathrm{n} / \mathrm{a}$ & $\mathrm{n} / \mathrm{a}$ & $\mathrm{n} / \mathrm{a}$ \\
\hline Oeste (vista al S) & $181^{\circ}$ & $00^{\circ} 42^{\prime}$ & $(-) 61^{\circ} 42^{\prime}$ & $\mathrm{n} / \mathrm{a}$ & $\mathrm{n} / \mathrm{a}$ & $\mathrm{n} / \mathrm{a}$
\end{tabular}

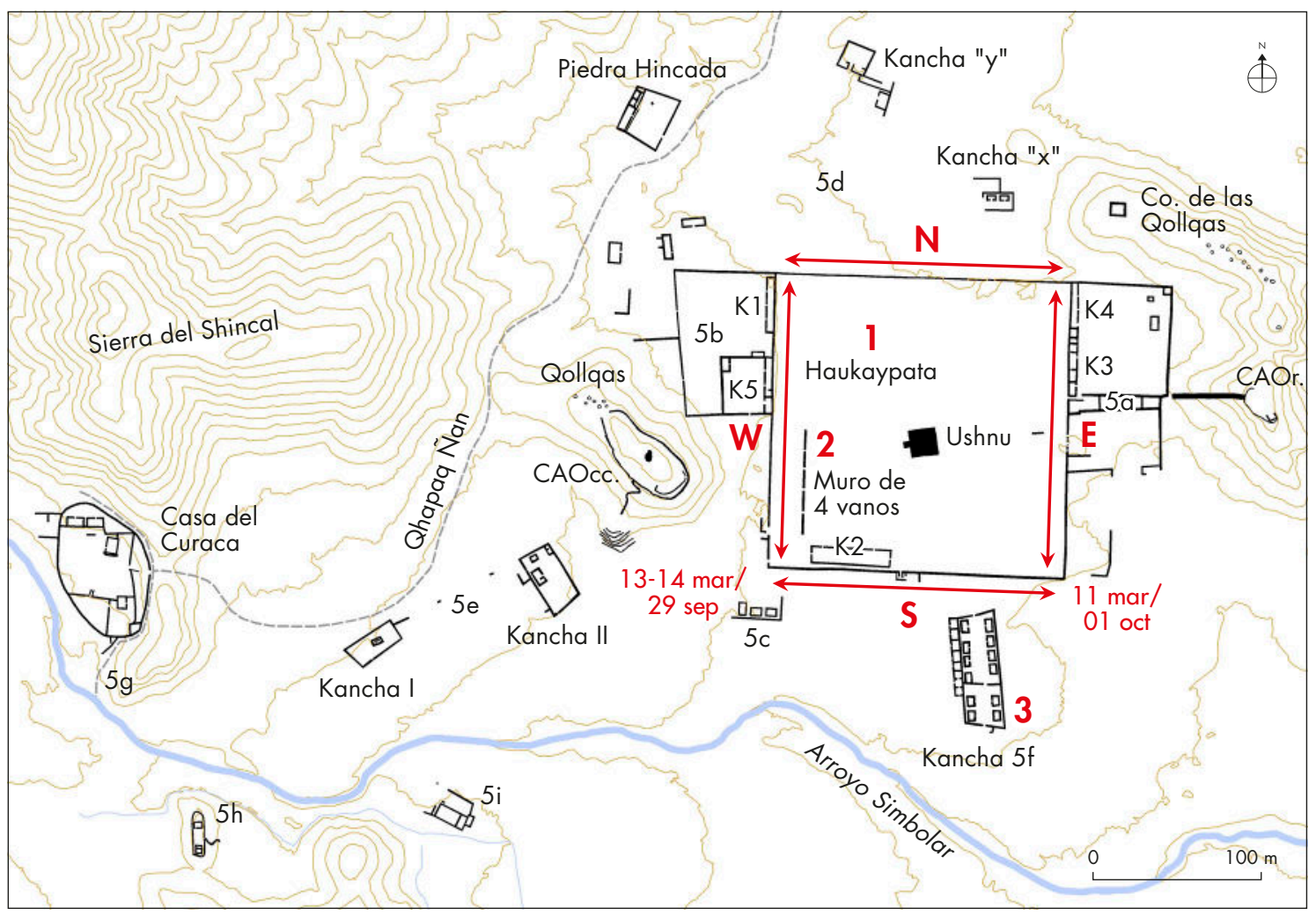

Figura 12. Orientaciones de la haukaypata. Figure 12. Orientations of the haukaypata. 
Tabla 4. Valores calculados correspondientes al muro de cuatro vanos del interior de la haukaypata (de norte a sur). Los valores fueron obtenidos con brújula y clisímetro, y posteriormente corregidos con la calculadora de declinación magnética y la plataforma Peak Finder. Table 4. Calculated values corresponding to the four-bay wall inside the Haukaypata (from north to south). The values were obtained with compass and clysimeter, and subsequently corrected with magnetic declination calculator and Peak Finder platform.

\begin{tabular}{c|c|c|c|c|c|c} 
ACCESO & AZ. CALC. & ALT. CALC. & DEC. CALC. & FECHA & DEC. (PL) & OBS \\
\hline A & $91^{\circ} 54^{\prime}$ & $03^{\circ} 36^{\prime}$ & $(-) 03^{\circ} 15^{\prime}$ & $12 \mathrm{mar} / 01 \mathrm{oct}$ & $(-) 03^{\circ} 41^{\prime}$ & P-SSEQ \\
\hline $\mathrm{B}$ & $91^{\circ} 54^{\prime}$ & $03^{\circ} 36^{\prime}$ & $(-) 03^{\circ} 15$ & $12 \mathrm{mar} / 01 \mathrm{oct}$ & $(-) 03^{\circ} 41^{\prime}$ & P-SSEQ \\
\hline $\mathrm{C}$ & $91^{\circ} 54^{\prime}$ & $03^{\circ} 36^{\prime}$ & $(-) 03^{\circ} 15^{\prime}$ & $12 \mathrm{mar} / 01 \mathrm{oct}$ & $(-) 03^{\circ} 41^{\prime}$ & P-SSEQ \\
\hline $\mathrm{D}$ & $91^{\circ} 54^{\prime}$ & $03^{\circ} 36^{\prime}$ & $(-) 03^{\circ} 15^{\prime}$ & $12 \mathrm{mar} / 01 \mathrm{oct}$ & $(-) 03^{\circ} 41^{\prime}$ & P-SSEQ
\end{tabular}
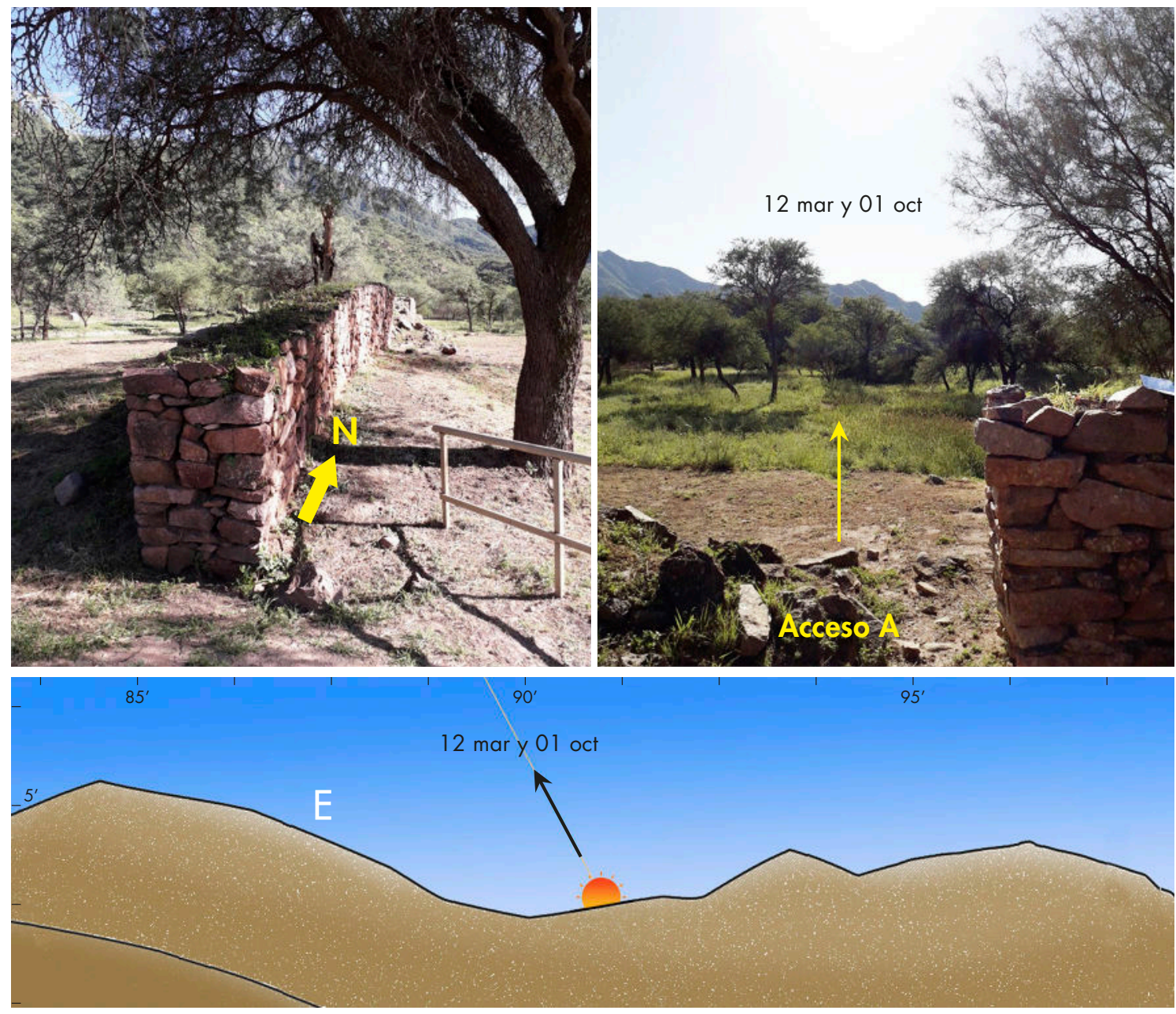

Figura 13. Vista al oriente, muro de cuatro vanos del interior de la haukaypata. Figure 13. View to the east, four-bay wall inside the haukaypata. 

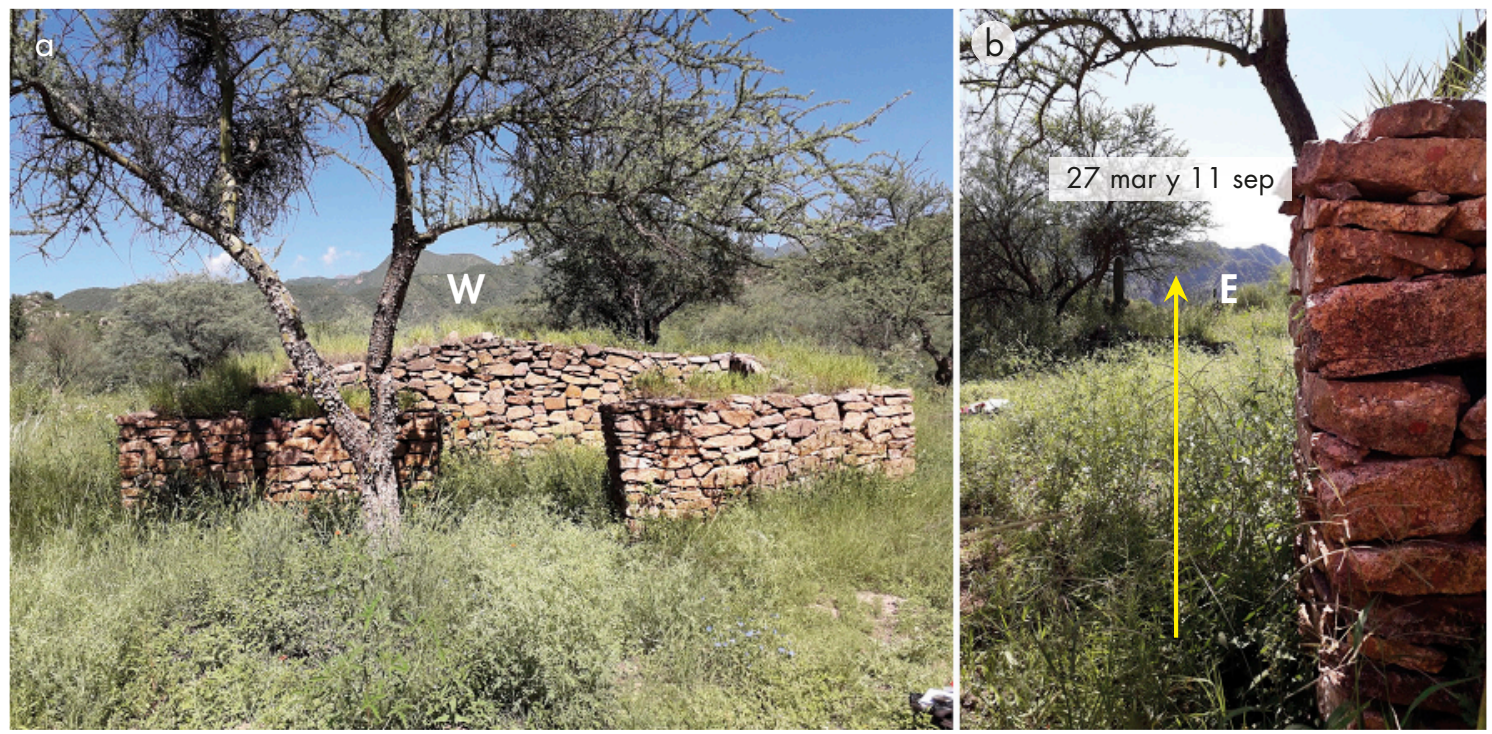

Figura 14. Recinto 1 de la kancha 5f: a) Vista al W; b) Vista al E. Figure 14. Enclosure 1 of the kancha 5f: a) View to the west; $\boldsymbol{b}$ ) View to the east.

La orientación general de los muros de la kancha $5 \mathrm{f}$ y los vanos de acceso a cada uno de sus 12 recintos (ubicados en dos patios internos en grupos de 8 y 4), más los 8 recintos externos (ubicados en la parte exterior del muro oeste), respetan la orientación este-oeste. La medición realizada en el Recinto 1 (R1), indica que su vano de acceso mira al oriente para los días 27 de marzo y 16 de septiembre (az.: $84^{\circ} 16^{\prime}$, alt.: $05^{\circ} 30^{\prime}, \delta$ : $\left.02^{\circ} 33^{\prime}, \delta(\mathrm{PL}): 02^{\circ} 07^{\prime}\right)$, muy cercanos a los equinoccios (fig. 14), y a una fecha similar a la detectada por Corrado et al. (2018) para la plataforma ushnu. En todos los casos, los cálculos asumen \pm 1 día de diferencia y ocurrirían en el horizonte cercano correspondiente al cerro Indio Dormido, que bien pudo tener una alta carga simbólica en tiempos prehispánicos y constituir también una huaca.

\section{DISCUSIÓN Y COMENTARIOS FINALES}

La ausencia de datos etnohistóricos que den cuenta de la existencia de líneas ceques para sitios del Noroeste Argentino constituye una de las limitaciones para hablar o definir un sistema de ceques. En este sentido, cabe recordar que el análisis formal de este sistema habría sido muy difícil de dotar de significados, si no hubiéramos contado con las crónicas como correlato de la información factual, tal como sucedió en el Cusco.
El sitio de El Shincal de Quimivil constituye un buen ejemplo de la arquitectura y la construcción social del paisaje en momentos Inca en el noroeste de Argentina. Su haukaypata, el ushnu, los cerros aterrazados Oriental y Occidental, el Intihuatana y el cerro Loma Larga, no solo generaron una base cuatripartita del espacio (Farrington 1999; Farrington et al. 2015, Giovannetti 2016), sino además posibilitaron la existencia de líneas de mira interpretadas como ceques. Su posición geográfica, cercana a los $28,5^{\circ}$ de latitud sur, en un principio nos condujo a pensar en la posibilidad de que este emplazamiento constituyera un marcador de la latitud geográfica y del fenómeno de paradas mayores de la Luna al sur. Esta hipótesis posteriormente se descartó de manera parcial debido a la inexistencia de marcadores de horizonte en ese sentido sur (Moyano et al. 2015).

Por otro lado, y aun cuando en El Shincal pudieron tener importancia las observaciones de las salidas solares en el solsticio de junio y para los días cercanos al cenit en el Cusco (Corrado et al. 2018, Lynch \& Giovannetti 2018, Corrado \& Giménez Benítez 2019), a partir de los datos presentados en este artículo destacamos la existencia de marcadores para las observaciones lunares (parada menor al norte y al sur), el solsticio de diciembre $\mathrm{y}$ fechas cercanas a los equinoccios, de acuerdo con las vistas realizadas en el ushnu y los cerros aterrazados.

Con respecto a la haukaypata se constató la orientación equinoccial de los muros norte y sur y de 
los vanos del muro interno. Ello no solo confirma las observaciones realizadas en otros sectores del sitio, como por ejemplo en la kancha $5 f$, sino que es estadísticamente consistente con otros sitios Inca del Collasuyu y el fenómeno del crossover (Moyano 2018). Entonces, con relación a la pregunta inicial de si es posible definir un sistema de ceques en El Shincal de Quimivil, consideramos lo siguiente:

El ushnu, en el centro de la plaza, al ser un punto de alto interés político, administrativo y ritual para los incas pudo funcionar como un lugar para distintas actividades, como la observación del cielo, aunque no necesariamente constituyó el centro de un sistema de ceques. Algunas de estas observaciones pudieron coincidir con líneas imaginarias y con elementos de la topografía local, posiblemente cerros huacas, localizados en los horizontes inmediatos o inclusive más allá. Estas líneas, si bien pudieron extenderse varios kilómetros, como plantean Lynch y Giovannetti (2018), somos cautos en asumirlas como ceques, pues aunque se trata de líneas imaginarias, son en estricto rigor muy concretas al ser un mecanismo cultural de apropiación del espacio, gracias a determinadas actividades humanas -líneas de visión- (de acuerdo con la descripción de la crónica de Cobo (1892 [1653]). Queda claro entonces, que las líneas norte-sur y esteoeste proyectadas desde el ushnu se relacionaron con la proyección mental y física de este "Nuevo Cusco", al vincular posiblemente la línea de la meridiana con el camino del Sol, formando cuadrantes y rumbos de horizonte gracias a los solsticios y equinoccios (Farrington 1999, Moyano et al. 2015). Desde un escenario hipotético, creemos que muchas de estas líneas ceques tendrían implicancias adivinatorias. Tal como hemos expuesto en trabajos previos (Farrington et al. 2015, Moyano et al. 2015), pudieron relacionar el ushnu o inclusive otros lugares de observación, como los cerros aterrazados Oriental y Occidental, Intihuatana y cerro Loma Larga, con la observación y predicción de eclipses, gracias al seguimiento de las fases de la Luna en sus ciclos sinódicos o en períodos mayores de 3,18 , 19 y 54 años (Moyano 2018).

Finalmente, consideramos que si bien todos los ceques son líneas (más o menos rectas), ello no significa que todas las líneas sean ceques. Decimos esto, pues el concepto de ceque incluye connotaciones políticas, administrativas y religiosas que, en el Cusco (y en gran parte de los Andes), estaban también relacionadas con grupos de parentesco y fechas específicas del calendario (siguiendo a Bauer 1998, 2016 \& Zuidema 2011). En tal sentido, somos prudentes en decir que en El Shincal de Quimivil, además de un posible "Nuevo Cusco", encontramos líneas imaginarias y marcadores astronómicos de horizonte, que pudieron iser o no...? parte de un sistema de ceques. Sabremos de ello en la medida en que futuras investigaciones y análisis comparativos, con datos etnográficos, entreguen información cualitativa más que estadística, sobre las orientaciones astronómicas, el uso de la arquitectura, la toponimia y el uso social del paisaje y el cielo en momentos Inca.

Nuestro aporte se enmarca entonces en la comprensión de este espacio urbano y arquitectónico como un escenario sumamente importante para ceremonias y actividades políticas, administrativas y religiosas ligadas al cielo en el Collasuyu. Un lugar todavía único que conecta la vida de los seres humanos con la sacralidad, la temporalidad y las huacas en los Andes del sur.

Agradecimientos Al Consejo Nacional de Investigaciones Científicas y Técnicas y a la Universidad Nacional de La Plata por el financiamiento. A la Lic. Paula Espósito -encargada del sitio arqueológico El Shincal de Quimivil- por su apoyo constante en la logística y trabajos de campo en el sitio. Asimismo, a la Municipalidad de Londres, a la Secretaría de Gestión Cultural de Catamarca y a la Dirección Provincial de Antropología. Agradecemos a Patricio Bustamante y al Lic. Diego Gobbo por su colaboración en la edición de las imágenes. En especial a nuestras familias. A los editores del Boletín del Museo Chileno de Arte Precolombino $\mathrm{y}$ a los evaluadores por sus comentarios y sugerencias que han ayudado a mejorar el artículo.

\section{NOTAS}

${ }^{1}$ El equinoccio es uno de los dos puntos de la esfera celeste en que el Sol cruza por el ecuador celeste (declinación igual a $00^{\circ}$ ). Para el hemisferio sur, marcará el inicio del otoño entre los días 20 y 21 de marzo; y el inicio de la primavera entre los días 22 y 23 de septiembre. En esos momentos el día tiene igual duración que la noche (Aveni 2005). El crossover corresponde al momento del año cuando la Luna (en plenilunio) cruza de un cuadrante del cielo al otro, a la inversa del Sol en el horizonte. En Europa se conoce como "equinoccio megalítico" y se vincula con la observación de la Luna llena del equinoccio de marzo, $07^{\circ}$ a $09^{\circ}$ al sur de la línea esteoeste, dando inicio a la primavera (Da Silva 2010).

${ }^{2}$ Trabajos recientes dan cuenta del azimut del muro sur del ushnu (84 $\left.38^{\prime}\right)$, marcando la salida del Sol para los días 26 de marzo y 16-17 de septiembre (Corrado et al. 2018). 


\begin{abstract}
${ }^{3}$ Con respecto a la orientación al poniente, existen hipótesis -de escaso fundamento metodológico- que relacionarían esta línea con el monte Pissis, localizado a $150 \mathrm{~km}$ de distancia, atribuyéndole cierta intencionalidad ritual con la escalinata del ushnu (Lynch \& Giovannetti 2018, siguiendo a Pino Matos). De acuerdo con nuestro estudio, esa línea (en caso de que hubiera existido) no tiene dirección hacia el Pissis, sino hacia un sector localizado más al sur de aquel. Por otro lado, aun cuando el Pissis pudiera tener alguna importancia para los incas, no es visible desde el sitio El Shincal ni tampoco desde los cerros más altos de la serranía homónima.

${ }^{4}$ En cuanto a las estructuras circulares de piedra, no descartamos que se trate de unidades chullpas, debido a su posición y asociación con determinados elementos sacros del paisaje.
\end{abstract}

${ }^{5}$ El conjunto correspondiente a la kancha 5 f era conocido anteriormente como conjunto Sinchihuasi.

${ }^{6}$ P-SSSD: presalida Sol solsticio diciembre, SsSD: salida Sol solsticio diciembre, P-PSSD: prepuesta Sol solsticio diciembre, PSSD: puesta Sol solsticio diciembre, P-sssJ: presalida Sol solsticio de junio, sssj: salida Sol solsticio junio, P-PSsJ: prepuesta Sol solsticio junio, PssJ: puesta Sol solsticio junio, P-SSEQ: presalida Sol equinoccio, SSEQ: salida Sol equinoccio, P-PSEQ: prepuesta Sol equinoccio, PSEQ: puesta Sol equinoccio, SLEN: salida Luna extrema norte, PLEN: puesta Luna extrema norte, SLES: salida Luna extrema sur, PLES: puesta luna extrema sur, SLMN: salida Luna menor norte, PLMN: puesta Luna menor norte, SLMS: salida Luna menor sur, PLMS: puesta Luna menor sur.

${ }^{7}<$ http://www.ngdc.noaa.gov/geomag-web/>

${ }^{8}<$ https://www.google.com/intl/es/earth/download/gep/ agree.html $>$,

$<$ https://www.peakfinder.org/>

${ }^{9} \delta=\operatorname{arcosen}[\operatorname{sen} \lambda \operatorname{sen} \mathrm{h}+\cos \lambda \cos \mathrm{h} \cos \mathrm{A}]$, donde: $\delta=$ declinación, $\lambda=$ latitud del sitio, $\mathrm{h}=$ altura del objeto (medido), $\mathrm{A}=$ azimut del objeto (medido).

${ }_{10}<\mathrm{http}: / /$ www.igik.edu.pl/>, <http://eclipse.gsfc.nasa. gov/eclipse.html $>$ shtml $>$

${ }^{11}<$ http://www.jaloxa.eu/resources/daylighting/sunpath.

${ }^{12}$ PL: paralaje lunar.

\section{REFERENCIAS}

AcuTo, F. 2012. Landscapes of inequality, spectacle and control: inka social order in provincial contexts. Revista Chilena de Antropología 25: 9-64.

Aveni, A. 2005. Observadores del cielo en el México antiguo. Mexico City: Fondo de Cultura Económica.

Barthel, T. 1986. El agua y el Festival de Primavera entre los atacameños. Allpanchis Phuturinga 28 (2): 147-184.

BAUER, B. S. 1998. The sacred landscape of the Inca: the Cusco ceque system. Austin: University of Texas Press.
Bauer, B. S. 2016. The Cusco ceque system as shown in the Exsus immeritus Blas Valera populo suo. Nawpa Pacha 36 (1): 23-34.

Bauer, B. S. \& Dearborn, D. S. P. 1998. Astronomía e imperio en los Andes. Cusco: Centro de Estudios Regionales Andinos Bartolomé Las Casas.

Bertonio, L. 1612. Vocabvlario dela lengva aymara: Primera y segvnda partes. Lima: Primeras ediciones peruanas, Biblioteca Nacional del Perú. <https://www.wdl.org/es/ item/13776/> [consultado: 22-04-20].

Betanzos, J. de. 1987 [1551]. Suma y narración de los Incas. Madrid: Atlas.

Сово, В. 1892 [1653]. Historia del Nuevo Mundo. Tomo III. Sevilla: Imprenta de E. Rasco.

Corrado, G., Giménez Benítez, S., Pino Matos, J. L. \& BALBI, N. 2018. Comparison between two inca sites, located north and south of the Tropic of Capricorn. Mediterranean Archaeology and Archaeometry 18 (4): 123-129.

Corrado, G. \& Giménez Benítez, S. 2019. Astronomía cultural en El Shincal de Quimivil. En Libro de Resúmenes del xx Congreso Nacional de Arqueología Argentina: 50 años de arqueologías, T. Costa da Silva, Ed., A. Laguens, M. Bonnin \& B. Marconetto, Comps., pp. 464-466. Córdoba: Facultad de Filosofía y Humanidades, Universidad Nacional de Córdoba.

Cornejo, L. \& SAAVEdra, M. 2018. El centro político inka en el extremo austral del Tawantinsuyu (Chile central). Boletín del Museo Chileno de Arte Precolombino 23 (1): 133-158.

Couso, M. G., Moralejo, R. A., Iácona, A., Giambelluca, R., Gianelli, J., OchoA, M. A., Aventín Moretti, M. \& Quaranta, G. A. 2013. La problemática en torno a la reutilización del sitio Loma Larga (Londres, Catamarca). In Libro de Resúmenes del XVIII Congreso Nacional de Arqueología Argentina: Arqueología Argentina en el Bicentenario de la Asamblea General Constituyente de 1813, J. R. Bárcena \& S. E. Martín, Eds., pp. 447-448. La Rioja: Universidad Nacional de La Rioja, INCIHUSA-CONICET.

Criado Boado, F. 1991. Construcción social del espacio y reconstrucción arqueológica del paisaje. Boletín de Antropología Americana 24: 5-29.

DA Silva, C. M. 2010. Neolithic cosmology: the equinox and the Spring full moon. Journal of Cosmology 9: 2207-2216.

D’Altroy, T. N. 2003. Los Incas. Barcelona: Ariel.

Del Río, M. M. 2005. Etnicidad, territorialidad y colonialismo en los Andes: tradición y cambio entre los Soras de los siglos XVI y XVII. La Paz: Instituto de Estudios Bolivianos.

Descola, P. 2012. Más allá de naturaleza y cultura. Buenos Aires-Madrid: Amorrortu.

FARrington, I. 1999. El Shincal: un Cusco del Kollasuyu. In Actas del XII Congreso Nacional de Arqueología Argentina, C. Diez Marín, Ed., Tomo I, pp. 53-62. La Plata: Facultad de Ciencias Naturales y Museo, unlP.

Farrington, I., Moyano, R. \& Díaz, G. 2015. El paisaje ritual en El Shincal de Quimivil. La importancia de 
los estudios arqueoastronómicos. In Una capital inka al sur del Kollasuyu: El Shincal de Quimivil, R. Raffino, L. Iácona, R. Moralejo, D. Gobbo \& M. G. Couso, Eds., pp. 41-61. Buenos Aires: Fundación de Historia Natural Félix de Azara.

Garcilaso de la Vega, I. 2005 [1609]. Comentarios Reales de los Incas, II. Mexico City: Fondo de Cultura Económica.

Giovannetti, M. 2016. Fiestas y ritos inka en El Shincal de Quimivil. La presencia del Tawantinsuyu en la provincia de Catamarca. Buenos Aires: Punto de Encuentro.

González Holguín, D. 1952 [1608]. Vocabulario de la Lengva General de todo el Perv llamada Lengva Qquichua, o del Inca. Lima: Imprenta Santa María.

Guamán Poma de Ayala, F. 2008 [1615]. Nueva corónica y buen gobierno. Mexico City: Fondo de Cultura Económica.

Hyslop, J. 1990. Inka settlement planning. Austin: University of Texas Press.

InGOLD, T. 1993. The temporality of the landscape. World Archaeology 25 (2): 152-174.

IWANISZEWSKI, S. 1995. Archaeoastronomy and cultural astronomy: methodological issues. In Atti dei Convegni Lincei 121. Archeologia e astronomia: esperienze e prospettive future, pp. 17-26. Rome: Accademia Nazionale dei Lincei.

IwANISZEWSKI, S. 2007. La arqueología de alta montaña frente al paisaje montañés en México central: problemas, interpretaciones, perspectivas epistemológicas. In Páginas en la nieve, estudios sobre la montaña en México, M. Loera, S. Iwaniszewski \& R. Cabrera, Coords., pp. 9-28. Mexico City: Instituto Nacional de Antropología e Historia.

Lefebvre, H. 1976. Espacio y política. Barcelona: Península.

Leibowicz, I., Moyano, R., Ferrari, A., Acuto, F. \& Jacob, C. 2016. Archaeoastronomy on inca sites in the Argentine northwest. Journal of Skyscape Archaeology 2 (2): 165-187.

Leibowicz, I., Moyano, R., Ferrari, A., Acuto, F. \& Jacob, C. 2018. Culto y peregrinaje inka en el nevado de Cachi, Salta, Argentina. Nuevos datos en Arqueología de Alta Montaña. Ñawpa Pacha 38 (2): 183-202.

Lynch, J. \& Giovannetti M. A. 2018. Paisajes inka en el centro-oeste de Catamarca (Argentina). Latin American Antiquity 29 (4): 754-773.

Mariscotti De Görlitz, A. M. 1978. Pachamama santa tierra. Contribución al estudio de la religión autóctona en los Andes centro-meridionales. Berlin: Gebr. Mann.

Martz de la Vega, H., Moyano, R., Iwaniszewski, S. \& Pérez Negrete, M. 2013. Hansómetro. Programa libre para cómputo de arqueoastronomía en Excel. Mexico City: Escuela Nacional de Antropología e Historia.

MAtos, R. 1999. La cerámica Inca. In Los Incas: arte y símbolos, F. Pease, Ed., pp. 109-167. Lima: Fondo Editorial del Banco de Crédito del Perú.

Maurtua, V. M. (Ed.). 1906. Juicio de límites entre el Perú y Bolivia: prueba peruana presentada al Gobierno de la República Argentina, Tomo 8. Madrid: Imprenta de los Hijos de M. G. Hernández.
Molina, C. de. 1947 [1573]. Ritos y fábulas de los incas. Colección Eurindia 14. Buenos Aires: Futuro.

Monteverde Sotil, L. R. 2011. Los incas y la fiesta de la Situa. Chungara 43 (2): 243-256.

Moralejo, R. A. 2011. Los Inkas al sur del Valle de Hualfín: organización del espacio desde una perspectiva paisajística. Tesis doctoral, Facultad de Ciencias Naturales y Museo, Universidad Nacional de La Plata. <http://sedici.unlp.edu. ar/handle/10915/5242> [consultado: 20-12-18].

Moralejo, R. A. \& Gobbo, D. 2017. Desde el camino: los SIG y El Shincal de Quimivil (Londres, Catamarca, Noroeste argentino). In Nuevas tendencias en el estudio de los caminos, S. Chacaltana, E. Arkush \& G. Marcone, Eds., pp. 322-345. Lima: Gráfica Industrial R\&S.

Moralejo, R. A., Gobbo, J. D., Del Cogliano, D. \& Pinto, L. 2018. Aplicación de tecnología LIDAR en El Shincal de Quimivil, Londres, Catamarca. Arqueología 24 (3): 165-184.

Moyano, R. 2010. El ushnu y la astronomía de horizonte en Viña del Cerro. Chungara 42 (2): 419-432.

Moyano, R. 2011. Sub-tropical astronomy in southern Andes: the ceque system in Socaire, Atacama, northern Chile. In Proceedings of the International Astronomical Union, 7 (S278): Archaeoastronomy and ethnoastronomy: building bridges between Cultures, C. L. N. Ruggles, Ed., pp. 93-105. Cambridge: Cambridge University Press.

Moyano, R. 2014. Astronomical Observation on Inca Ushnus in Southern Andes. In Inca sacred space landscape, site and symbol in the Andes, F. Meddens, C. McEwan, K. Willis \& N. Branch, Eds., pp. 187-196. London: Archetype Publications.

Moyano, R. 2018. "De noche también sale el Sol". Arqueoastronomía y ciclos lunares en los Andes del Collasuyu. Cuadernos del Instituto Nacional de Antropología y Pensamiento Latinoamericano, Series Especiales 6 (1): 58-83.

Moyano, R., Díaz, M. G., Farrington, I., Moralejo, R., Couso, M. G. \& Raffino, R. 2015. Arqueoastronomía en El Shincal de Quimivil: análisis preliminar de un sitio inca en la franja del lunisticio mayor al sur. In Arqueología y Paleontología de la Provincia de Catamarca, R. del Valle \& M. A. López, Eds., pp. 249-260. Buenos Aires: Fundación de Historia Natural Félix de Azara.

Murra, J. 1972. El "control vertical" de un máximo de pisos ecológicos en la economía de las sociedades andinas. Huánuco: Universidad Hermilio Valdizán.

Pino Matos, J. L. 2005. El ushnu y la organización espacial astronómica en la sierra central del Chinchaysuyu. Estudios Atacameños 29: 143-161.

Raffino, R. 1983. Los Inkas del Kollasuyu. La Plata: Ramos Americana.

Raffino, R. (Ed.). 2004. El Shincal Quimivil. San Fernando del Valle de Catamarca: Sarquís.

Raffino, R., Alvis, R., Baldini, L., Olivera, D. \& Raviña M. 1982. Hualfín-El Shincal-Watungasta. Tres casos de urbanización Inka en el N.O. argentino. In Actas del IX Congreso Nacional de Arqueología, pp. 470-497. La Serena: 
Sociedad Chilena de Arqueología-Museo Arqueológico de La Serena.

Raffino, R. A., Moralejo, R. A., Iacona, L. A. \& Gobbo, D. 2020. Arquitectura del paisaje: las awkaypatas del Tawantinsuyu como espacio de poder. In Yachay wasi: the house of knowledge of I. S. Farrington, L. A. Dunbar, R. Parkes, C. Gant-Thmpson \& D. Tybussek, Eds., pp. 169-190. Oxford: BAR Publishing.

Rowe, J. H. 1981. Una relación de los adoratorios del antiguo Cuzco. Histórica 5 (2): 209-261.

Ruggles, C. L. N. (Ed.). 2015. Handbook of archaeoastronomy and ethnoastronomy. Nueva York-Heidelberg-DordrechtLondon: Springer Science, Business Media.

SoJA, E. W. 1971. The political organization of space. Washington: Association of American Geographers, Commission on College Geography.

ŠPRAJC, I. 2001. Orientaciones astronómicas en la arquitectura prehispánica del centro de México. Mexico City: Instituto Nacional de Antropología e Historia.

Stehberg, R. \& Sotomayor, G. 2012. Mapocho incaico. Boletín del Museo Nacional de Historia Natural 61: 85-149.
Tichy, F. 1983. El patrón de asentamientos con sistema radial en la meseta central de México: ¿Sistemas Ceque en Mesoamérica? In Jahrbuch für Geschichte von Staat, Wirtschaft und Gesellschaft Lateinamerikas 20, pp. 61-84. Colonia-Viena: Böhlau.

ZIóLKowski, M. 2015. Pachapvnancha. El calendario metropolitano del Estado Inca. Arequipa: El Lector.

Zuidema, R. T. 1989. Reyes y guerreros: ensayos de cultura andina. Lima: Fomciencias.

Zuidema, R. T. 1995. El Sistema de ceques del Cuzco. La organización social de la capital de los incas. Lima: Fondo Editorial de la Pontificia Universidad Católica del Perú.

Zuidema, R. T. 2007. The inca calendar, the ceque system, and their representation in Exsul immeritus. In Per bocca d'altri. Indios, gesuiti e spagnoli in due documenti segreti sul Perú del XvII secolo, L. Laurencich, D. Domenici \& S. Venturoli, Ed., pp. 75-104. Bologna: Alma Digital Library.

Zuidema, R. T. 2011. El calendario inca. Tiempo y espacio en la organización ritual del Cusco. La idea del pasado. Lima: Fondo Editorial del Congreso del Perú-Fondo Editorial de la Pontificia Universidad Católica del Perú. 